\title{
SDRE-Based Near Optimal Control System Design for PM Synchronous Motor
}

\author{
Ton Duc Do, Han Ho Choi, Member, IEEE and Jin-Woo Jung, Member, IEEE
}

\begin{abstract}
This paper presents a nonlinear optimal speed controller based on a state-dependent Riccati equation (SDRE) for permanent magnet synchronous motor (PMSM). An SDREbased near optimal load torque observer is also proposed to provide the load torque information for the controller. In both designs, the stability is analytically proven and Taylor series method is used to find an approximate solution because the SDRE cannot be directly solved. The SDRE-based optimal controller and observer can ensure better control performance such as no overshoot and fast transient response in speed tracking than the linear conventional controllers such as LQ regulator and PI controller even under the variations of the model parameters and load torque. The proposed SDRE-based control strategy is implemented on a PMSM testbed using TMS320F28335 DSP. The simulation and experimental results are given to prove the feasibility of the proposed control scheme.
\end{abstract}

Index Terms-Nonlinear control, observer, optimal control, permanent magnet synchronous motor (PMSM), speed control, state-dependent Riccati equation (SDRE), Taylor series method.

\section{INTRODUCTION}

Permanent magnet synchronous motor (PMSM) is one of the most popular ac motors in industry because of good controllability and high efficiency. In industrial PMSM drive applications, PID or linear quadratic (LQ) regulator has been extensively adopted since its implementation is easy [1]-[2]. However, these linear control methods cannot assure high control performance (e.g., fast transient response, zero steadystate error, and robustness) because it is highly vulnerable to parameter variations and external disturbances. Consequently, it is quite challenging to precisely and quickly control the PMSMs with the nonlinear dynamic model. Recently, to cope with the limitations of the linear control methods, many researchers have proposed various nonlinear control techniques such as adaptive control [3]-[5], fault-tolerant control [6], robust control [7], intelligent control [8], sliding mode control [9], direct torque control [10]-[11], model

Manuscript received May 13, 2011; revised August 25, 2011; accepted for publication September 22, 2011. This work was supported by the Energy Efficiency \& Resources of the Korea Institute of Energy Technology Evaluation and Planning (KETEP) grant funded by the Ministry of Knowledge Economy, Republic of Korea (No. 2010T100200468).

Copyright (c) 2011 IEEE. Personal use of this material is permitted. However, permission to use this material for any other purposes must be obtained from the IEEE by sending a request to pubs-permissions@ieee.org.

The authors are with the Division of Electronics and Electrical Engineering, Dongguk University-Seoul, Seoul 100-715, South Korea (email: jinwjung@dongguk.edu). predictive control [12], and fuzzy control [13].

Of nonlinear feedback control strategies, nonlinear optimal control has been applied to various industrial applications. This control method is an extension of quadratic optimal control for linear systems that should solve an algebraic Riccati equation (ARE) to satisfy the desired control performance. Particularly, one of the nonlinear optimal control methods is referred to as a state-dependent Riccati equation (SDRE) based control because the SDRE is a function of the system's states that should be solved to construct a nonlinear control law. It is known that the SDREbased control method is a systematic and efficient way to design the nonlinear feedback controllers and is applicable to a wide range of nonlinear systems [14]-[23]. In design of the SDRE-based optimal controllers, the solution of the nonlinear control problems can be approximated by using some numerical methods. Therefore, the SDRE approach can be an attractive alternative to many engineers who design the controllers of the nonlinear systems. Comprehensive simulation studies have demonstrated the effectiveness of the SDRE method as a successful technique for controlling an artificial human pancreas [14], high-pressure chemical vapor deposition reactors [15], spacecrafts [16], robots [17], ducted fans [18], magnetic levitation systems [19], tandem hot metal strip rolling process [20], and tethered satellite systems [21]. Recently, the SDRE control method has been applied to control the speed of the PMSMs [22]-[23]. In [22], an adaptive SDRE technique based on gradient-type neutral networks is presented, and an SDRE-based controllerobserver is introduced in [23]. However, both methods are quite complicated to implement and do not fully show the results that can verify its control performance, respectively.

In this paper, a nonlinear optimal controller based on a state-dependent Riccati equation (SDRE) is proposed to control the speed of the PMSM. Also, an SDRE-based optimal load torque observer is designed to supply the controller with the load torque information. In both designs, the stability is analytically proven and Taylor series numerical method is used to approximate the solution of each SDRE. The SDRE-based optimal controller and observer can guarantee better control performance such as no overshoot and fast transient response in speed tracking than the linear conventional controllers such as LQ regulator and PI controller even under the variations of the model parameters and load torque. The proposed SDRE-based control algorithm is implemented on a prototype PMSM drive with 
TMS320F28335. Simulation and experimental results are shown to justify the feasibility of the proposed control scheme.

\section{SDRE-BASEd NeAR OPtimal CONTROLler Design}

\section{A. SDRE Parameterization of Optimal Controller Gain and Stability Analysis}

In the synchronously rotating $d-q$ reference frame, a threephase surface-mounted PMSM can be described by the following nonlinear equations:

$$
\left\{\begin{array}{l}
\dot{\omega}=k_{1} i_{q s}-k_{2} \omega-k_{3} T_{L} \\
\dot{i}_{q s}=-k_{4} i_{q s}-k_{5} \omega+k_{6} V_{q s}-\omega i_{d s} \\
\dot{i}_{d s}=-k_{4} i_{d s}+k_{6} V_{d s}+\omega i_{q s}
\end{array}\right.
$$

where

$$
\begin{aligned}
& k_{1}=\frac{3}{2} \frac{1}{J} \frac{p^{2}}{4} \lambda_{m}, k_{2}=\frac{B}{J}, k_{3}=\frac{p}{2 J}, \\
& k_{4}=\frac{R_{s}}{L_{s}}, k_{5}=\frac{\lambda_{m}}{L_{s}}, k_{6}=\frac{1}{L_{s}},
\end{aligned}
$$

$\omega \quad$ Electrical rotor angular speed;

$i_{q s} \quad q$-axis current;

$i_{d s} \quad d$-axis current;

$V_{q s} \quad q$-axis voltage;

$V_{d s} \quad d$-axis voltage;

$T_{L} \quad$ Load torque;

$p \quad$ Number of poles;

$R_{S} \quad$ Stator resistance;

$L_{s} \quad$ Stator inductance;

$J \quad$ Rotor inertia;

$B \quad$ Viscous friction coefficient;

$\lambda_{m} \quad$ Magnetic flux.

The speed error, $q$-axis current error, and desired $q$-axis current can be defined as

$$
\begin{aligned}
& \tilde{\omega}=\omega-\omega_{d}, \tilde{i}_{q s}=i_{q s}-i_{q s d}, \\
& i_{q s d}=\left(k_{2} \omega_{d}+\dot{\omega}_{d}+k_{3} T_{L}\right) / k_{1}
\end{aligned}
$$

where

$\begin{array}{cl}\omega_{d} & \text { Desired electrical rotor angular speed; } \\ \tilde{\omega} & \text { Electrical rotor angular speed error; } \\ i_{q s d} & \text { Desired } q \text {-axis current; } \\ \widetilde{i}_{q s} & q \text {-axis current error. }\end{array}$

Let the control inputs $V_{q s}$ and $V_{d s}$ be represented as

$$
V_{q s}=u_{f f q}+u_{f b q}, \quad V_{d s}=u_{f f d}+u_{f b d}
$$

where

$u_{f f q}, u_{f b q} q$-axis feedforward and feedback control laws, respectively;

$u_{f f d}, u_{f b d} d$-axis feedforward and feedback control laws, respectively.

The feedforward control laws $u_{f f q}, u_{f f d}$ are defined as

$$
\begin{aligned}
& u_{f f q}=\frac{1}{k_{6}}\left(k_{4} i_{q s d}+k_{5} \omega_{d}+i_{d s} \omega_{d}+\dot{i}_{q s d}\right) \\
& u_{f f d}=-\frac{1}{k_{6}}\left(\tilde{i}_{q s} \omega_{d}+\omega i_{q s d}\right)
\end{aligned}
$$

Using (3) to (5), the dynamic model (1) can be expressed as the following error dynamics

$$
\dot{x}=A(x) x+B u
$$

where $x=\left[\begin{array}{lll}\tilde{\omega} & \tilde{i}_{q s} & i_{d s}\end{array}\right]^{T}, u=\left[\begin{array}{ll}u_{f b q} & u_{f b d}\end{array}\right]^{T}$, and

$$
A(x)=\left[\begin{array}{ccc}
-k_{2} & k_{1} & 0 \\
-k_{5} & -k_{4} & -\tilde{\omega} \\
0 & \tilde{\omega} & -k_{4}
\end{array}\right], \quad B=\left[\begin{array}{cc}
0 & 0 \\
k_{6} & 0 \\
0 & k_{6}
\end{array}\right]
$$

In (7), $A(x)$ is a continuous matrix for all $x$ and $B$ is a constant matrix. Finally, the optimal feedback control law is given by

$$
u=-K(x) x=-R^{-1} B^{T} L(x) x
$$

where $K(x)$ is an SDRE gain matrix, and $L(x)$ is a unique, symmetric, positive definite solution of the following SDRE

$$
L(x) A(x)+{ }^{*}-L(x) B R^{-1} B^{T} L(x)+Q=0
$$

where $*$ represents blocks that are readily inferred by symmetry, $Q \in R^{3 \times 3}$ is a constant symmetric positive semidefinite weighting matrix, and $R \in R^{3 \times 3}$ is a constant symmetric positive definite weighting matrix. Then by referring to [24] the following theorem can be established.

Theorem 1: Consider the closed-loop system of (6) and the control law $u$ defined in (8). Then the equilibrium of the closed-loop system (6) is asymptotically stable.

Proof: Firstly, the state-dependent coefficient matrix $A(x)$ is rewritten as sum of a constant matrix $A_{0}$ and a statedependent incremental matrix $\Delta A(x)$ which satisfies $\Delta A(0)=0$,

$$
A(x)=A_{0}+\Delta A(x)
$$

where

$$
A_{0}=\left[\begin{array}{ccc}
-k_{2} & k_{1} & 0 \\
-k_{5} & -k_{4} & 0 \\
0 & 0 & -k_{4}
\end{array}\right], \Delta A(x)=\left[\begin{array}{ccc}
0 & 0 & 0 \\
0 & 0 & -\tilde{\omega} \\
0 & \tilde{\omega} & 0
\end{array}\right]
$$

Let $L_{0}$ be the solution of the following ARE

$$
L_{0} A_{0}+{ }^{*}-L_{0} B R^{-1} B^{T} L_{0}+Q=0
$$

and $L(x)=L_{0}+\Delta L(x)$. Therefore, a state-dependent optimal gain matrix $K(x)$ can be represented as the sum of a constant matrix $K_{0}$ and an incremental matrix $\Delta K(x)$,

$$
u=-\left(K_{0}+\Delta K(x)\right) x
$$

where

$$
K_{0}=R^{-1} B^{T} L_{0}, \Delta K(x)=R^{-1} B^{T} \Delta L(x)
$$

Thus the controlled nonlinear dynamics can be expressed as the following form

$$
\dot{x}=\left(A_{0}-B K_{0}\right) x+h(x)
$$

where let $h(x)=g(x) x=(\Delta A(x)-B \Delta K(x)) x$.

Then the system (15) can be regarded as a linear system problem satisfying the property below 


$$
\lim _{\|x\| \rightarrow 0} \frac{\|h(x)\|}{\|x\|}=0
$$

It can be easily inferred from the following inequality

$$
\|h(x)\| \leq\|g(x)\|\|x\| \leq(\|\Delta A(x)\|-\|B\|\|\Delta K(x)\|)\|x\|
$$

where the norms of the state-dependent incremental matrices $\Delta A(x), \Delta K(x)$ are continuous and equal to zero at the origin. Then, $\|g(x)\|$ converges to zero as $\|x\|$ goes to zero. Consequently, $h(x)$ meets the condition (16). In other words, let $\zeta>0$ be given. Hence, there exists $\delta$ such that $\|h(x)\| \leq \zeta\|x\|$ for all $\|x\| \leq \delta$. Let $\|x(0)\| \leq \delta$, then the solution $x$ of (16) exists and satisfies $\|x\| \leq \delta$ as long as $\hat{t}>0$. For $t \in[0, \hat{t})$, the solution of (16) satisfies

$$
\|x(t)\| \leq\left\|e^{\left(A_{0}-B K_{0}\right) t}\right\|\|x(0)\|+\zeta \int_{0}^{t}\left\|e^{\left(A_{0}-B K_{0}\right)(t-\tau)}\right\|\|x(\tau)\| d \tau
$$

From the linear quadratic regulator (LQR) theory, with the matrix $K_{0}$ which is calculated in (14), all eigenvalues of $\left(A_{0}-\right.$ $B K_{0}$ ) have negative real parts. It means the existence of $\beta>0$ such that $\operatorname{Re}(\lambda)<-\beta$ for all eigenvalues of $\left(A_{0}-B K_{0}\right)$. Thus there exists a positive constant $G$ such that

$$
\left\|e^{\left(A_{0}-B K_{0}\right) t}\right\| \leq G e^{-\beta t}
$$

so that

$$
\|x(t)\| \leq G e^{-\beta t}\|x(0)\|+\zeta G \int_{0}^{t} e^{-\beta(t-\tau)}\|x(\tau)\| d \tau
$$

Multiplying both sides of (20) by $e^{\beta t}$ and borrowing from the Gronwall inequality, the following equation can be found

$$
e^{\beta t}\|x(t)\| \leq G\|x(0)\| e^{\zeta G t} \text { or }\|x(t)\| \leq G\|x(0)\| e^{-(\beta-\zeta G) t}
$$

for all $t>0$ such that $\|x\| \leq \delta$. The initial condition domain is restrained further by choosing $\zeta \in(0, \beta / G)$. If $\delta$ is equivalent to $\zeta$ and $\gamma \in(0, \delta), \delta_{0}=\min (\delta, \gamma / G)$ is adopted. Hence for $\|x(0)\| \leq$ $\delta_{0}$, it is given that $\|x(t)\|<\gamma \leq \delta_{0}$ for all $t>0$ and $x=0$ is stable. Besides, (21) holds for all $t>0$ in case that $\|x(0)\| \leq \delta$. It can be concluded that the nonlinear system is asymptotically stable at the origin $(x=0)$ because $(\beta-\zeta G)>0$.

Remark 1: It should be noted that the optimal feedback control law obtained from (8) and (9) is the suboptimal solution of the optimal control problem associated with nonlinear dynamics (6) by minimizing the following performance index [24],

$$
J(x, u)=\frac{1}{2} \int_{t_{0}}^{\infty}\left(x^{T} Q x+u^{T} R u\right) d t
$$

\section{B. Near Optimal Controller Design by Taylor Series Method}

It is not easy to analytically solve the SDRE (9) because $A(x)$ is a state-dependent matrix. In this subsection, Taylor series numerical method is used to approximate the solution of the SDRE (9).

By introducing a new variable $\varepsilon$, the state-dependent matrix $A(x)$ can be rewritten as

$$
A(x)=A_{0}+\varepsilon \Delta A(x)
$$

The solution of the SDRE (9) can be represented as the following Taylor series

$$
L(x, \varepsilon)=\sum_{n=0}^{\infty} \varepsilon^{n} L_{n}(x)=\left.L(x)\right|_{\varepsilon=0}+\left.\frac{\partial L(x)}{\partial \varepsilon}\right|_{\varepsilon=0} \varepsilon+\ldots
$$

where each $L_{n}(x)$ matrix is symmetric because $L(x)$ is symmetric.

Inserting (23) and (24) for $A(x)$ and $L(x)$ into the SDRE (9), the following equation is obtained

$$
\begin{aligned}
& \left(\sum_{n=0}^{\infty} \varepsilon^{n} L_{n}(x)\right)\left(A_{0}+\varepsilon \Delta A(x)\right)+* \\
& \quad-\left(\sum_{n=0}^{\infty} \varepsilon^{n} L_{n}(x)\right) B R^{-1} B^{T}\left(\sum_{n=0}^{\infty} \varepsilon^{n} L_{n}(x)\right)+Q=0
\end{aligned}
$$

By arranging like powers of $\varepsilon$ and then assigning the coefficients to zero, the equations to calculate all $L_{n}$ matrices are given as

$$
\begin{gathered}
L_{0} A_{0}+{ }^{*}-L_{0} B R^{-1} B^{T} L_{0}+Q=0 \\
L_{1} A_{1}+L_{0} \Delta A+*=0 \\
\vdots \\
L_{n} A_{1}+L_{n-1} \Delta A+*-\sum_{k=1}^{n-1} L_{k} B R^{-1} B^{T} L_{n-k}=0
\end{gathered}
$$

where $A_{1}=A_{0}-B R^{-1} B^{T} L_{0}$.

It is noted that (26) is the algebraic Riccati equation (ARE) corresponding to $\left(A_{0}, B\right)$, whereas (27) and (28) are the statedependent Lyapunov equations. It is understood that this methodology converges locally to the solution of the SDRE (9) because $A(x)$ is continuous and $B$ is constant [25]. For transforming (27) and (28) to algebraic Lyapunov equations, the state-dependent incremental matrix is rewritten as

$$
\Delta A(x)=\left[\begin{array}{ccc}
0 & 0 & 0 \\
0 & 0 & -\tilde{\omega} \\
0 & \tilde{\omega} & 0
\end{array}\right]=\tilde{\omega}\left[\begin{array}{ccc}
0 & 0 & 0 \\
0 & 0 & -1 \\
0 & 1 & 0
\end{array}\right]=\tilde{\omega} \Delta A_{C}
$$

By establishing $L_{n}(x)=(\tilde{\omega})^{n} L_{n}^{C}$ where $L_{n}{ }^{C}$ is a constant matrix, (26) to (28) can be expressed as the following

$$
\begin{gathered}
L_{0}^{C} A_{0}+*-L_{0}^{C} B R^{-1} B^{T} L_{0}^{C}+Q=0 \\
L_{1}^{C} A_{1}+L_{0}^{C} \Delta A_{C}+*=0 \\
\vdots \\
L_{n}^{C} A_{1}+L_{n-1}^{C} \Delta A_{C}+*-\sum_{k=1}^{n-1} L_{k}^{C} B R^{-1} B^{T} L_{n-k}^{C}=0
\end{gathered}
$$

Therefore, the solution of the SDRE (9) can be approximated by solving (30) to (32). Finally, the near optimal feedback control law is given by

$$
u=-\left(R^{-1} B^{T} \sum_{n=0}^{N}(\tilde{\omega})^{n} L_{n}^{C}\right) x=-\left(\sum_{n=0}^{N}(\tilde{\omega})^{n} K_{n}\right) x
$$

where $K_{n}=R^{-1} B^{T} L_{n}^{C}$ and $N$ is the number of members of the series computed offline.

Fig.1 illustrates the block diagram of the proposed SDREbased near optimal speed controller. 


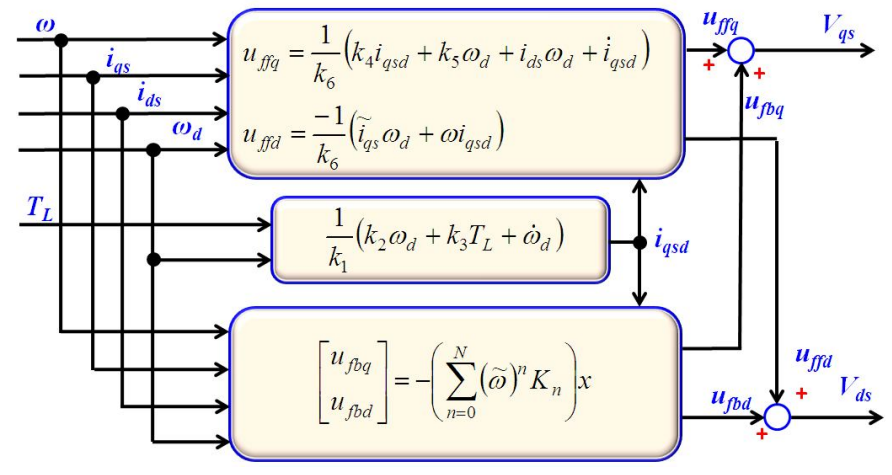

Fig. 1. Block diagram of the proposed SDRE-based near optimal speed controller.

\section{SDRE-BASEd NeAR Optimal LOAD TORQue ObSERVER DESIGN}

\section{A. SDRE Parameterization of Optimal Load Torque Observer Gain and Stability Analysis}

As shown in (6), the SDRE-based speed control approach requires some information to design a state feedback control law: electrical rotor angular speed $\omega, q$-axis current $i_{q s}, d$-axis current $i_{d s}$, and load torque $T_{L}$. In this paper, it is assumed that $\omega, i_{q s}$, and $i_{d s}$ are available. Generally, the load torque $T_{L}$ is estimated in industrial applications since a toque meter is so expensive and deteriorates system reliability. In this section, we will design an SDRE-based near optimal load torque observer which can accurately estimate $T_{L}$.

For a fixed sampling interval, the load torque does not vary suddenly. Thus, assume that $T_{L}$ is constant, and its derivative $\dot{T}_{L}$ is equal to zero. Based on $\dot{T}_{L}=0$ and (1), the fourth-order dynamic model is given as follows:

$$
\dot{x}_{o}=A_{o}\left(x_{o}\right) x_{o}+u_{o}
$$

where

$$
x_{o}=\left[\begin{array}{c}
T_{L} \\
\omega \\
i_{q s} \\
i_{d s}
\end{array}\right], A_{o}\left(x_{o}\right)=\left[\begin{array}{cccc}
0 & 1 & 0 & 0 \\
-k_{3} & -k_{2} & k_{1} & 0 \\
0 & -k_{5} & -k_{4} & -\omega \\
0 & 0 & \omega & -k_{4}
\end{array}\right], u_{o}=\left[\begin{array}{c}
0 \\
0 \\
k_{6} V_{q s} \\
k_{6} V_{d s}
\end{array}\right]
$$

Then, the load torque observer model can be expressed as

$$
\begin{aligned}
& \dot{\hat{x}}_{o}=A_{o}\left(\hat{x}_{o}\right) \hat{x}_{o}+M\left(\hat{x}_{o}\right) y_{o}-M\left(\hat{x}_{o}\right) C_{o} \hat{x}_{o}+u_{o} \\
& y_{o}=C_{o} x_{o} \\
& \hat{T}_{L}=C_{T} \hat{x}_{o}
\end{aligned}
$$

where $\hat{T}_{L}$ is an estimate of $T_{L}, M\left(\hat{x}_{o}\right) \in R^{4 \times 3}$ is an observer gain matrix, and

$$
\hat{x}_{o}=\left[\begin{array}{c}
\hat{T}_{L} \\
\hat{\omega} \\
\hat{i}_{q s} \\
\hat{i}_{d s}
\end{array}\right], C_{o}=\left[\begin{array}{llll}
0 & 1 & 0 & 0 \\
0 & 0 & 1 & 0 \\
0 & 0 & 0 & 1
\end{array}\right], C_{T}=\left[\begin{array}{l}
1 \\
0 \\
0 \\
0
\end{array}\right]^{T}
$$

Similar to (10), $A_{o}\left(x_{o}\right)$ is rewritten as sum of a constant matrix $\bar{A}_{o}$ and a state-dependent incremental matrix $\Delta A_{o}\left(x_{o}\right)$

$$
A_{o}\left(x_{o}\right)=\bar{A}_{o}+\Delta A_{o}\left(x_{o}\right)
$$

where

$$
\bar{A}_{o}=\left[\begin{array}{cccc}
0 & 0 & 0 & 0 \\
-k_{3} & -k_{2} & k_{1} & 0 \\
0 & -k_{5} & -k_{4} & 0 \\
0 & 0 & 0 & -k_{4}
\end{array}\right], \Delta A_{o}\left(x_{o}\right)=\left[\begin{array}{cccc}
0 & 0 & 0 & 0 \\
0 & 0 & 0 & 0 \\
0 & 0 & 0 & -\omega \\
0 & 0 & \omega & 0
\end{array}\right]
$$

Then $P_{0}$, which is the solution at $x_{0}=0$, is the solution of the following ARE

$$
\bar{A}_{o} P_{0}+*-P_{0} C_{o}^{T} R_{o}^{-1} C_{o} P_{0}+Q_{o}=0
$$

Define $\Delta P\left(x_{\mathrm{o}}\right)=P\left(x_{\mathrm{o}}\right)-P_{0}$ where $P\left(x_{\mathrm{o}}\right)$ solves the following SDRE for some $Q_{0} \geq 0, R_{0}>0$

$$
A_{o}\left(x_{o}\right) P\left(x_{o}\right)+*-P\left(x_{o}\right) C_{o}^{T} R_{o}^{-1} C_{o} P_{o}\left(x_{o}\right)+Q_{o}=0
$$

Thus, a state-dependent optimal gain matrix $M\left(x_{o}\right)$ is calculated as

$$
M\left(x_{o}\right)=M_{0}+\Delta M\left(x_{o}\right)
$$

where $M_{0}=P_{0} C_{o}^{T} R_{o}^{-1}$ and $\Delta M\left(x_{o}\right)=\Delta P\left(x_{o}\right) C_{o}^{T} R_{o}^{-1}$.

Here, $M_{0}$ is the gain matrix that stabilizes $\left(\bar{A}_{o}, C_{o}^{T}\right)$. Consequently, $\left(\bar{A}_{o}-M_{0} C_{o}\right)$ has all eigenvalues with negative real parts. Moreover, $\Delta A\left(x_{0}\right)$ and $\Delta P\left(x_{0}\right)$ are small and bounded in a neighborhood of the origin because they are zero at $x_{0}=0$ and continuous. Therefore, $\Delta M(0)$ is equal to zero and $\Delta M\left(x_{0}\right)$ is small in a neighborhood of the origin.

Theorem 2: Consider the following SDRE

$$
A_{o}\left(\hat{x}_{o}\right) P\left(\hat{x}_{o}\right)+{ }^{*}-P\left(\hat{x}_{o}\right) C_{o}^{T} R_{o}^{-1} C_{o} P_{o}\left(\hat{x}_{o}\right)+Q_{o}=0
$$

where $Q_{o} \in R^{4 \times 4}$ is a constant symmetric positive semidefinite weighting matrix, and $R_{o} \in R^{3 \times 3}$ is a constant symmetric positive definite weighting matrix. Also, assume that the load torque observer gain matrix $M\left(\hat{x}_{o}\right)$ is given by

$$
M\left(\hat{x}_{o}\right)=P\left(\hat{x}_{o}\right) C_{o}^{T} R_{o}^{-1}
$$

Then the estimated state in (35) converges locally asymptotically to the state.

Proof: The proof can be completed similarly to that of Theorem 1.

Remark 2: It should be noted that the observer gain matrix which is calculated in (40) and (41) is the suboptimal solution of the optimal control problem associated with the following nonlinear dynamics

$$
\dot{\hat{x}}_{o}=A_{o}^{T}\left(\hat{x}_{o}\right) \hat{x}_{o}+C_{o}^{T} u_{o}
$$

and the performance index [24] is given as

$$
J_{o}\left(\hat{x}_{o}, u_{o}\right)=\frac{1}{2} \int_{t_{0}}^{\infty}\left(\hat{x}_{o}^{T} Q_{o} \hat{x}_{o}+u_{o}^{T} R_{o} u_{o}\right) d t
$$

\section{B. Near Optimal Observer Design by Taylor Series Method}

The SDRE optimal observer gain matrix (41) can be obtained in the manner of the SDRE-based optimal controller. That is, the solution of the SDRE (40) can be approximated by 


$$
M\left(\hat{x}_{o}\right)=\left(\sum_{n=0}^{N_{o}} P_{n}^{C} \hat{\omega}^{n}\right) C_{o}^{T} R_{o}^{-1}=\sum_{n=0}^{N_{o}} M_{n} \hat{\omega}^{n}
$$

where $M_{n}=P_{n}^{C} C_{o}^{T} R_{o}^{-1}$ and all $P_{n}{ }^{C}$ matrices can be achieved by solving the following equations

$$
\begin{gathered}
\bar{A}_{o} P_{0}^{C}+{ }^{*}-P_{0}^{C} C_{o}^{T} R_{o}^{-1} C_{o} P_{0}^{C}+Q_{o}=0 \\
A_{o 1} P_{1}^{C}+P_{0}^{C} \Delta A_{o C}^{T}+*=0 \\
\vdots \\
A_{o 1} P_{n}^{C}+\Delta A_{o C} P_{n-1}^{C}+*-\sum_{k=1}^{n-1} P_{k}^{C} C_{o}^{T} R_{o}^{-1} C_{o} P_{n-k}^{C}=0
\end{gathered}
$$

where $A_{o 1}=\bar{A}_{o}-P_{0}^{C} C_{o}^{T} R_{o}^{-1} C_{o}, \Delta A_{o C}=\left[\begin{array}{cccc}0 & 0 & 0 & 0 \\ 0 & 0 & 0 & 0 \\ 0 & 0 & 0 & -1 \\ 0 & 0 & 1 & 0\end{array}\right]$.

Remark 3: For the case $N_{o}=0$, the above SDRE-based observer is reduced to the Kalman-Bucy optimal observer minimizing the performance index $E\left(e^{T} e\right)$ that implies the expectation value of $e^{T} e$ for the following linear time-invariant model

$$
\dot{x}_{o}=\bar{A}_{o} x_{o}+u_{o}+d, \quad y_{o}=C_{o} x_{o}+v
$$

where $d \in R^{4}, v \in R^{3}$ are independent white Gaussian noise signals with $E(d)=0, E(v)=0, E\left(d d^{T}\right)=Q_{o}$, and $E\left(v v^{T}\right)=R_{o}$.

Fig. 2 depicts the block diagram of the proposed SDREbased near optimal load torque observer.

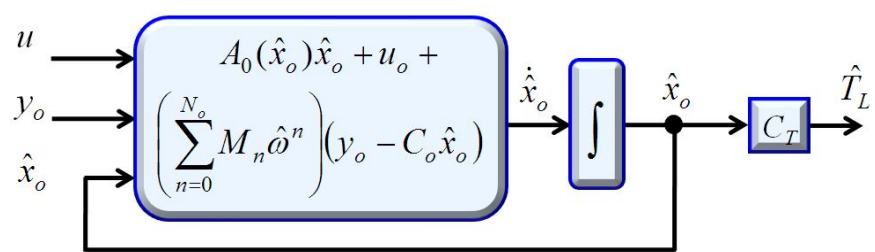

Fig. 2. Block diagram of the proposed SDRE-based near optimal load torque observer.

\section{SDRE-Based Near Optimal SpeEd Control LaW WITH LOAD TORQUE OBSERVER}

By solving the Riccati and Lyapunov equations (30) to (32) and (45) to (47) with respect to the SDRE-based optimal controller and observer, a load-torque-observer-based control law can be designed. It is noticed that the solution matrices $L_{k}^{C}$ and $P_{k}^{C}$ of these equations can be easily computed by using the Matlab's command "care" and "lyap" as follows:

$L O C=\operatorname{care}(A O, B, Q, R)$;

$Q 1=\angle O c^{*} d A c+d A c^{* *} L O c$;

$A 1=A 0-B^{*} \operatorname{inv}(R)^{*} B^{* *} L O C$;

$L 1 c=\operatorname{lyap}(A 1, Q 1)$;

$L n c=\operatorname{lyap}(A 1, Q n)$
$P O c=$ care (Aobar', Co', Qo, Ro);

$Q 01=d A o c{ }^{*} P 0 c+P 0 c^{*} d A o c ;$

Ao1=Aobar $-P 0 c^{*} \mathrm{Co}{ }^{*}$ inv $(R o)^{*} \mathrm{Co}$;

$P 1 c=$ lyap (Ao1', Qo1);

$\vdots$

$P n c=$ lyap (Ao1', Qon);

where $L k c$ and $P k c$ represent $L_{k}{ }^{C}$ and $P_{k}^{C}(k=0,1, \ldots n)$, and AO, Al, dAc, Aobar, Aol, dAoc, Qo, Ro, Co are used for $A_{0}, A_{1}$, $\Delta A_{C}, \bar{A}_{o}, A_{o 1}, \Delta A_{o C}, Q_{o}, R_{o}, C_{o}$, respectively.

Finally, by using the estimated load torque $\hat{T}_{L}$ instead of $T_{L}$, the observer-based optimal control inputs can be expressed as:

$$
\begin{aligned}
{\left[\begin{array}{c}
V_{q s} \\
V_{d s}
\end{array}\right]=} & -\left(R^{-1} B^{T} \sum_{n=0}^{N}(\tilde{\omega})^{n} L_{n}^{C}\right) \hat{x} \\
& +\left[\begin{array}{c}
\frac{1}{k_{6}}\left(k_{4} \hat{i}_{q s d}+k_{5} \omega_{d}+i_{d s} \omega_{d}+\dot{\hat{i}}_{q s d}\right) \\
-\frac{1}{k_{6}}\left(\hat{\tilde{i}}_{q s} \omega_{d}+\omega \hat{i}_{q s d}\right)
\end{array}\right]
\end{aligned}
$$

where $\quad \hat{i}_{q s d}=\left(k_{2} \omega_{d}+k_{3} \hat{T}_{L}+\dot{\omega}_{d}\right) / k_{1} \quad, \quad \hat{\tilde{i}}_{q s}=i_{q s}-\hat{i}_{q s d}$, $\hat{x}=\left[\widetilde{\omega}, \hat{\vec{i}}_{q s}, i_{d s}\right]^{T}$.

Remark 4: It should be noted that the proposed SDREbased control strategy can be applicable to various electric drive applications which can be represented as (6). The design procedure of the proposed control scheme can be generalized as follows:

Step 1: Choose appropriate weighting matrices $Q_{o}$ and $R_{o}$ for the observer design through intensive simulation studies.

Step 2: Solve algebraic Ricatti equation (45) and Lyapunov equations (46), (47) to obtain the solution matrices $P_{n}{ }^{C}$.

Step 3: Calculate the observer gain matrices $M_{n}$, and construct the load torque observer (35).

Step 4: Choose appropriate weighting matrices $Q$ and $R$ for the controller design through intensive simulation studies.

Step 5: Solve algebraic Ricatti equation (30) and Lyapunov equations (31), (32) to obtain the solution matrices $L_{n}{ }^{C}$.

Step 6: Calculate the near optimal control gain matrices $K_{n}$. Finally, construct the load torque observer-based near optimal speed control law (49).

\section{CASE STUdy FOR VerificATIONS}

To confirm the effectiveness of the proposed SDRE-based optimal control system design, let us consider a prototype PMSM with the following nominal parameters: rated power $P_{\text {rated }}=1 \mathrm{HP}$; rated phase current $I_{\text {rated }}=3.94 \mathrm{~A}$; rated torque $T_{\text {rated }}=3.9 \mathrm{~N} \cdot \mathrm{m} ; p=12 ; R_{s}=0.99 \Omega ; L_{s}=5.82 \mathrm{mH} ; \lambda_{m}=$ $7.92 \times 10^{-2} \mathrm{~V} \cdot \mathrm{sec} / \mathrm{rad} ; \quad J=12.08 \times 10^{-4} \mathrm{~kg} \cdot \mathrm{m}^{2} ; \quad B=3 \times 10^{-4}$ 
$\mathrm{N} \cdot \mathrm{m} \cdot \mathrm{sec} / \mathrm{rad}$. Then the coefficients of the system model (1) are given as:

$$
\begin{aligned}
& k_{1}=3539.6, k_{2}=0.2484, k_{3}=34968.8 \\
& k_{4}=170.1, k_{5}=13.6, k_{6}=171.82
\end{aligned}
$$

By solving the algebraic Riccati equation (45), the Lyapunov equations (46) and (47) with $N_{o}=2$, the load torque observer gain matrices can be calculated as

$$
\begin{aligned}
& M_{0}=10^{4} \times\left[\begin{array}{ccc}
-0.0241 & 0.0041 & -0.0000 \\
1.0555 & 0.1663 & -0.0000 \\
0.1663 & 0.9690 & -0.0000 \\
-0.0000 & -0.0000 & 0.9831
\end{array}\right] \\
& M_{1}=\left[\begin{array}{ccc}
-0.0000 & -0.0000 & -0.0359 \\
0.0000 & 0.0000 & 0.0804 \\
0.0000 & 0.0000 & 0.0005 \\
0.0804 & 0.0005 & -0.0000
\end{array}\right] \\
& M_{2}=10^{-5} \times\left[\begin{array}{ccc}
-0.0129 & 0.5413 & -0.0000 \\
0.0292 & -0.3786 & -0.0000 \\
-0.3786 & -0.0799 & 0.0000 \\
-0.0000 & 0.0000 & -0.0269
\end{array}\right]
\end{aligned}
$$

By solving the ARE (30), the Lyapunov equations (31) and (32) with $N=2$, the near optimal control gain matrices can be computed as

$$
\begin{aligned}
K_{0} & =\left[\begin{array}{ccc}
31.5397 & 56.4596 & 0.0000 \\
-0.0000 & 0.0000 & 43.7423
\end{array}\right] \\
K_{1} & =\left[\begin{array}{ccc}
-0.0000 & 0.0000 & 0.0005 \\
-0.0039 & 0.0005 & -0.0000
\end{array}\right] \\
K_{2} & =10^{-6} \times\left[\begin{array}{ccc}
0.3660 & -0.1550 & -0.0000 \\
-0.0000 & -0.0000 & -0.0647
\end{array}\right]
\end{aligned}
$$

Based on the observer gain matrices (50) to (52) and the control gain matrices (53) to (55), it is noted that $M_{0}$ and $M_{1}$ are much more dominant observer gain matrices than $M_{2}$, while $K_{0}$ and $K_{1}$ are also much more critical control gain matrices than $K_{2}$. Therefore, in this paper, only $N_{\mathrm{o}}=1$ and $N=$ 1 are chosen, which can guarantee good performance of the SDRE-based near optimal control system without much computational effort.

Finally, the observer-based optimal control inputs can be given by

$$
\begin{aligned}
{\left[\begin{array}{c}
V_{q s} \\
V_{d s}
\end{array}\right] } & =-\left[\begin{array}{c}
31.5397 \tilde{\omega}+56.4596 \hat{\tilde{i}}_{q s}+0.0005 i_{d s} \tilde{\omega} \\
-0.0039 \tilde{\omega}^{2}+0.0005 \tilde{\omega} \hat{\tilde{i}}_{q s}+43.7423 i_{d s}
\end{array}\right] \\
& +\left[\begin{array}{c}
0.9900 \hat{i}_{q s d}+0.0792 \omega_{d}+0.0006\left(i_{d s} \omega_{d}+\dot{\hat{i}}_{q s d}\right) \\
-0.0006\left(\hat{\tilde{i}}_{q s} \omega_{d}+\omega \hat{i}_{q s d}\right)
\end{array}\right]
\end{aligned}
$$

Fig. 3 shows the configuration of a prototype PMSM drive system to prove the proposed control methodology. It comprises a PMSM, an electrical brake, a three-phase PWM inverter with a TI TMS320F28335 DSP.

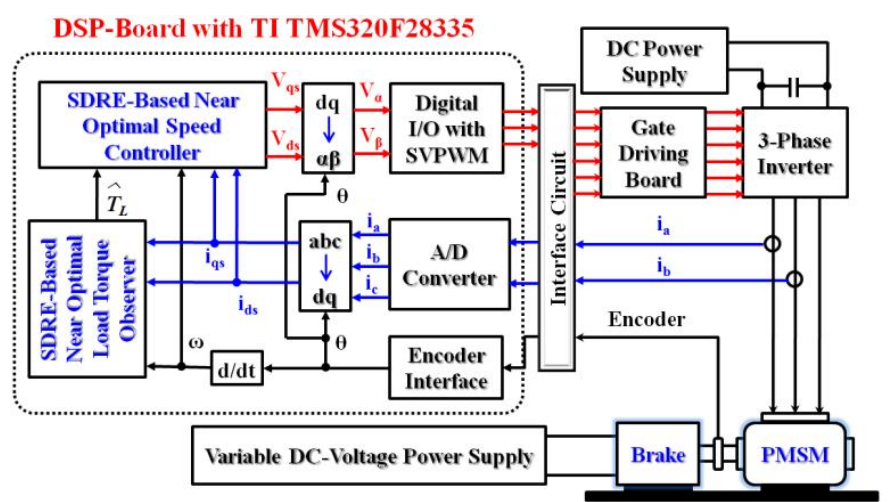

Fig. 3. Configuration of a prototype PMSM drive system.

As described in Fig. 3, the proposed SDRE-based near optimal observer estimates the load torque $T_{L}$, and then the estimated load torque $\hat{T}_{L}$ is provided to the SDRE-based near optimal speed controller. The rotor position $(\theta)$ and two phase currents $\left(i_{a}, i_{b}\right)$ are measured by means of an encoder and current sensors, respectively. Taking into account a trade-off between the system efficiency and the control performance, the sampling frequency as well as the PWM frequency is designed as $5 \mathrm{kHz}$. Additionally, a space vector PWM (SVPWM) technique of various PWM methods is used to regulate the phase currents flowing into the PMSM.

For comparisons, this paper presents the simulation results of three control methods: proposed control method $\left(N_{\mathrm{o}}=1\right.$ and $N=1)$, proposed control method $\left(N_{\mathrm{o}}=0\right.$ and $\left.N=0\right)$, and conventional proportional-integral (PI) control method. It should be noted that when $N$ is equal to zero, the proposed controller is very similar to a LQ regulator (with a little difference in $u_{f f q}$ and $u_{f f d}$ ). Three different control schemes have been simulated using Matlab/Simulink, which is a very powerful simulation tool, under the following three cases:

\section{- Case 1: Speed Transient Response}

1) The desired speed $\left(\omega_{d}\right):-188.5 \mathrm{rad} / \mathrm{sec} \rightarrow 188.5$ $\mathrm{rad} / \mathrm{sec} \rightarrow-188.5 \mathrm{rad} / \mathrm{sec}$

2) Nominal motor parameters;

3) Load torque $T_{L}=1 \mathrm{~N} \cdot \mathrm{m}$.

\section{- Case 2: Speed Transient Response}

1) The desired speed $\left(\omega_{d}\right):-188.5 \mathrm{rad} / \mathrm{sec} \rightarrow 188.5$ $\mathrm{rad} / \mathrm{sec} \rightarrow-188.5 \mathrm{rad} / \mathrm{sec}$

2) $150 \%$ variations of some motor parameters $\left(R_{s}, L_{s}, J\right)$, i.e, $R_{s}=1.485 \Omega, L_{s}=8.73 \mathrm{mH}, J=18.1 \times 10^{-4} \mathrm{~kg} \cdot \mathrm{m}^{2}$;

3) Load torque $T_{L}=1.5 \mathrm{~N} \cdot \mathrm{m}$.

\section{- Case 3: Load Torque Transient Response}

1) The desired speed $\left(\omega_{d}\right)=188.5 \mathrm{rad} / \mathrm{sec}$;

2) $150 \%$ variations of some motor parameters $\left(R_{s}, L_{s}, J\right)$, i.e, $R_{s}=1.485 \Omega, L_{s}=8.73 \mathrm{mH}, J=18.1 \times 10^{-4} \mathrm{~kg} \cdot \mathrm{m}^{2}$;

3) Load torque $T_{L}: 1 \mathrm{~N} \cdot \mathrm{m} \rightarrow 2 \mathrm{~N} \cdot \mathrm{m} \rightarrow 1 \mathrm{~N} \cdot \mathrm{m}$.

Case 1 and Case 2 show the speed transient response under nominal parameters and some parameter variations, respectively when the desired speed $\left(\omega_{d}\right)$ changes and the load 
torque $\left(T_{L}\right)$ is constant. Meanwhile, Case 3 shows the load torque transient behavior in the presence of motor parameter variations when the desired speed $\left(\omega_{d}\right)$ is constant and the load torque $\left(T_{L}\right)$ changes with a step.

Figs. 4 to 6 show the simulation results of the proposed control method $\left(N_{\mathrm{o}}=1\right.$ and $\left.N=1\right)$ under Case 1 to Case 3, respectively, and each figure shows the waveforms $\left(\omega, \omega_{d}, \widetilde{\omega}\right.$, $\left.i_{q s}, i_{d s}, T_{L}, \hat{T}_{L}, i_{a}\right)$. In all cases, the speed errors $\tilde{\omega}$ in steadystate are almost zero. In Figs. 4 and 5, the speed errors vary up to $2.67 \%$ and $3.88 \%$ from the reference in the transient time when the desired speed $\left(\omega_{d}\right)$ varies at $0.3 \mathrm{sec}$ and $0.7 \mathrm{sec}$. Also, in both figures, the speed response has no overshoot and a short settling time $(0.033 \mathrm{sec}, 0.033 \mathrm{sec})$. Fig. 6 shows that the motor speed $(\omega)$ is very stable during the transient time when the load torque suddenly changes from $1 \mathrm{~N} \cdot \mathrm{m}$ to $2 \mathrm{~N} \cdot \mathrm{m}$ and vice versa. Particularly, Figs. 4 to 6 show that the load torque $T_{L}$ is accurately estimated by the SDRE-based near optimal observer.

Figs. 7 to 9 show the simulation results of the proposed control method $\left(N_{\mathrm{o}}=0\right.$ and $\left.N=0\right)$ under Case 1 to Case 3, respectively. In Figs. 7 to 9, the speed errors $\tilde{\omega}$ in steady-state are almost zero. However, Figs. 7 and 8 show that the speed errors change by $43.5 \%$ and $55.63 \%$ from the reference in the transient time when the desired speed $\left(\omega_{d}\right)$ varies. In Fig. 7, the speed response has no overshoot but a longer settling time $(0.085 \mathrm{sec})$. Meanwhile, Fig. 8 shows that the speed behavior has a bigger overshoot $(5.31 \%)$ and a longer settling time $(0.114 \mathrm{sec})$. In Fig. 9, it is shown that the motor speed changes up to $10.85 \%$ during the transient when the load torque abruptly varies from $1 \mathrm{~N} \cdot \mathrm{m}$ to $2 \mathrm{~N} \cdot \mathrm{m}$ at $0.3 \mathrm{sec}$ and vice versa at $0.7 \mathrm{sec}$. Note that the load torque observer does not work well in all cases because the estimated load torque has some steady-state error not to be neglected.

Next, Figs. 10 to 12 show the simulation results of the conventional PI control method under Case 1 to Case 3, respectively. Note that the PI speed controller is used in an outer loop and the PI current controller is used in an inner loop. The gains of both PI controllers are determined by the tuning rule [26], and the bandwidths are designed as $\omega_{\text {speed }}=$ $2 \pi \cdot 16 \mathrm{rad} / \mathrm{sec}$ and $\omega_{\text {current }}=2 \pi \cdot 160 \mathrm{rad} / \mathrm{sec}$, respectively. Thus, the PI control law can be expressed by the following equation,

$$
\left[\begin{array}{c}
V_{q s} \\
V_{d s}
\end{array}\right]=-\left[\begin{array}{c}
k_{P i q} \tilde{i}_{q s}+k_{\text {Iiq }} \int_{0}^{t} \tilde{i}_{q s} d \tau \\
k_{P i d} i_{d s}+k_{\text {Iid }} \int_{0}^{t} i_{d s} d \tau
\end{array}\right]+\frac{1}{k_{6}}\left[\begin{array}{c}
k_{4} i_{q s}+k_{5} \omega+\omega i_{d s}+\dot{i}_{q s d} \\
k_{4} i_{d s}-\omega i_{q s}
\end{array}\right]
$$

where $i_{q s d}=k_{P \omega} \tilde{\omega}+k_{I \omega} \int_{0}^{t} \tilde{\omega} d \tau, k_{P i q}$ and $k_{\text {liq }}$ are the PI gains of the $q$-axis current controller, and $k_{P i d}$ and $k_{\text {Iid }}$ are the PI gains of the $d$-axis current controller. Meanwhile, $k_{P \omega}$ and $k_{I \omega}$ are the PI gains of the speed controller, respectively. As a result, when comparing the proposed control law (56) and the PI control law (57), it seems that there is no significant difference between both control laws regarding computational complexity.
Figs. 10 to 12 show that the steady-state speed errors are not considerable. Also, Fig. 10 shows that the speed error changes by $17.73 \%$ from the reference in the transient time. Fig. 11 shows that the speed error varies up to $31.19 \%$ during the transient time. In these figures, the speed behavior has a bigger overshoot $(15.34 \%, 30.66 \%)$ and a longer settling time $(0.087 \mathrm{sec}, 0.100 \mathrm{sec})$, respectively. Fig. 12 shows that the motor speed changes by $12.20 \%$ during the transient when the load torque varies with a step.

Table I summarizes the comparisons of control performance about three control strategies during the transient with respect to the simulation results.

TABLE I

COMPARISONS OF THREE CONTROL SCHEMES DURING THE TRANSIENT WITH RESPECT TO SIMULATION RESULTS

\begin{tabular}{|c|c|c|c|c|}
\hline \multicolumn{2}{|c|}{ Methods } & $\begin{array}{c}\text { Proposed } \\
\left(N_{o}=1, N=1\right)\end{array}$ & $\begin{array}{c}\text { Proposed } \\
\left(N_{o}=0, N=0\right)\end{array}$ & Conventional PI \\
\hline \multirow{2}{*}{$\begin{array}{c}\text { Conditions } \\
\text { Maximum } \\
\text { Speed } \\
\text { Error }\end{array}$} & Case 1 & $2.67 \%$ & $43.5 \%$ & $17.73 \%$ \\
\cline { 2 - 5 } & Case 2 & $3.88 \%$ & $55.63 \%$ & $31.19 \%$ \\
\hline \multirow{3}{*}{ Overshoot } & Case 3 & $0.97 \%$ & $10.85 \%$ & $12.20 \%$ \\
\cline { 2 - 5 } & Case 1 & $0 \%$ & $0 \%$ & $15.34 \%$ \\
\cline { 2 - 5 } & Case 2 & $0.83 \%$ & $5.31 \%$ & $30.66 \%$ \\
\hline \multirow{2}{*}{$\begin{array}{c}\text { Settling } \\
\text { Time }\end{array}$} & Case 3 & $0.97 \%$ & $9.85 \%$ & $12.09 \%$ \\
\cline { 2 - 5 } & Case 1 & $0.033 \mathrm{sec}$ & $0.085 \mathrm{sec}$ & $0.087 \mathrm{sec}$ \\
\cline { 2 - 5 } & Case 3 & $0.033 \mathrm{sec}$ & $0.114 \mathrm{sec}$ & $0.100 \mathrm{sec}$ \\
\hline
\end{tabular}

For evaluating the speed tracking performance of the proposed controller $\left(N_{\mathrm{o}}=1\right.$ and $\left.N=1\right)$ in a wide speed range, Fig. 13 illustrates the simulation results of the proposed control law under $150 \%$ variations of some motor parameters $\left(R_{s}, L_{s}\right.$ and $\left.J\right)$ when the load torque is equal to rated value (3.9 $\mathrm{N} \cdot \mathrm{m})$ and the reference speed $\left(\omega_{d}\right)$ increases up to the rated value (1850 RPM). That is, the desired motor speed $\left(\omega_{d}\right)$ suddenly increases from $565.49 \mathrm{rad} / \mathrm{sec}$ to $1162.39 \mathrm{rad} / \mathrm{sec}$ and then decreases from $1162.39 \mathrm{rad} / \mathrm{sec}$ to $565.49 \mathrm{rad} / \mathrm{sec}$. It is definitely verified that the proposed controller can accomplish good performance (maximum speed error: $1.25 \%$, overshoot: $0.28 \%$, settling time: $0 \mathrm{sec}$ ).

The proposed SDRE-based control algorithm is implemented on a prototype PMSM drive with TMS320F28335 as shown in Fig. 3. Figs. 14 to 16 show the experimental results about the speed response of the proposed SDRE-based near optimal control method $\left(N_{\mathrm{o}}=1\right.$ and $N=1$; $N_{\mathrm{o}}=0$ and $N=0$ ) and conventional PI-PI control method, respectively. Figs. 14 (a) to 16 (a) show the measured speed $(\omega)$, the desired speed $\left(\omega_{d}\right)$, and the speed error $(\tilde{\omega})$. Figs. 14 (b) to 16 (b) illustrate the $q$-axis current $\left(i_{q s}\right)$ and the $d$-axis current $\left(i_{d s}\right)$. Figs. 14 (c) to 16 (c) show the load torque $\left(T_{L}\right)$, the estimated load torque $\left(\hat{T}_{L}\right)$, and the phase $a$ current $\left(i_{a}\right)$. Also, Fig. 17 shows the experimental results about the load torque behavior of the proposed control method $\left(N_{\mathrm{o}}=1\right.$ and $N$ $=1)$ under $150 \%$ variations of some motor parameters $\left(R_{s}, L_{s}\right.$ and $J$ ) when the load torque changes with a step.

TABLE II

COMPARISONS OF THREE CONTROL SCHEMES DURING THE TRANSIENT WITH RESPECT TO EXPERIMENTAL RESULTS 


\begin{tabular}{|c|c|c|c|}
\hline Methods & $\begin{array}{c}\text { Proposed } \\
\left(N_{o}=1, N=1\right)\end{array}$ & $\begin{array}{c}\text { Proposed } \\
\left(N_{o}=0, N=0\right)\end{array}$ & Conventional PI \\
\hline $\begin{array}{c}\text { Maximum } \\
\text { Speed Error }\end{array}$ & $3.02 \%$ & $50.32 \%$ & $25.82 \%$ \\
\hline Overshoot & $0.73 \%$ & $8.13 \%$ & $42.13 \%$ \\
\hline Settling Time & $0.034 \mathrm{sec}$ & $0.121 \mathrm{sec}$ & $0.115 \mathrm{sec}$ \\
\hline
\end{tabular}

Table II summarizes the comparisons of control performance about three control methods during the transient with respect to the experimental results. It is clear that the proposed controller shows a better transient performance in comparison to the conventional LQ regulator or PI controller.
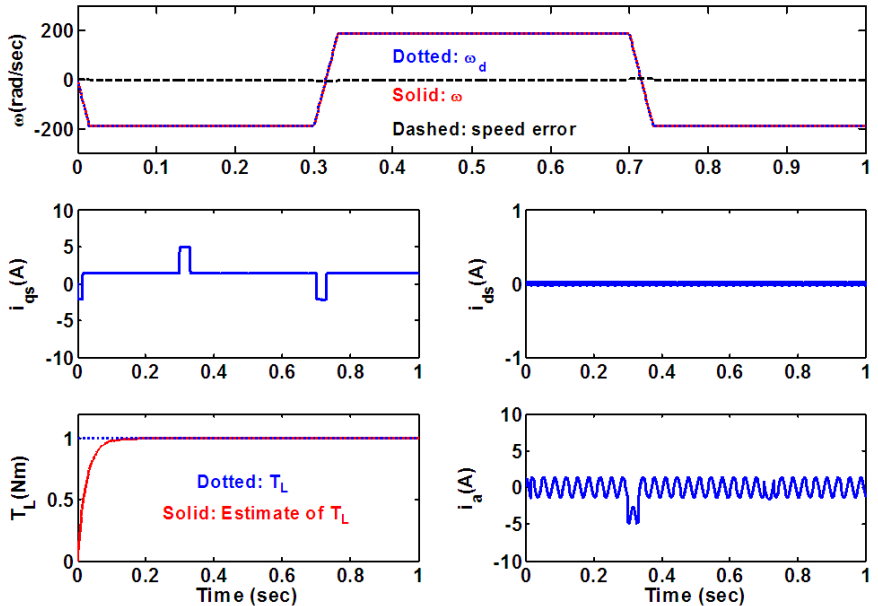

Fig. 4. Simulation results of the proposed control method $\left(N_{\mathrm{o}}=1\right.$ and $\left.N=1\right)$ under Case 1.
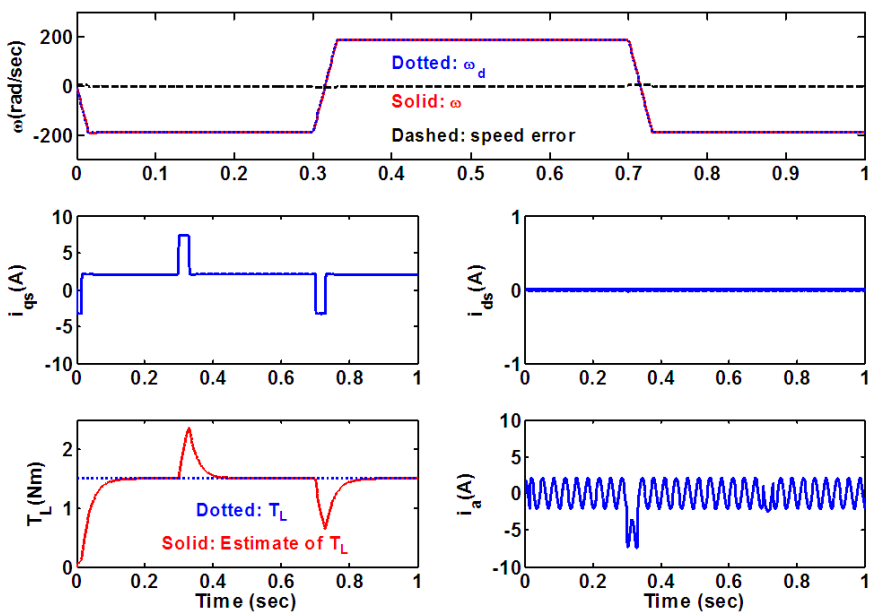

Fig. 5. Simulation results of the proposed control method $\left(N_{\mathrm{o}}=1\right.$ and $\left.N=1\right)$ under Case 2.
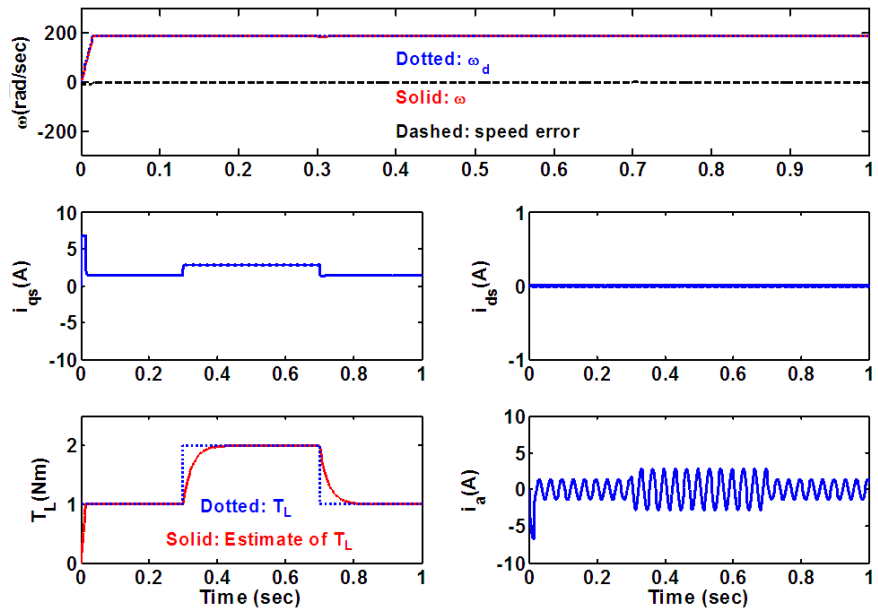

Fig. 6. Simulation results of the proposed control method $\left(N_{\mathrm{o}}=1\right.$ and $\left.N=1\right)$ under Case 3.
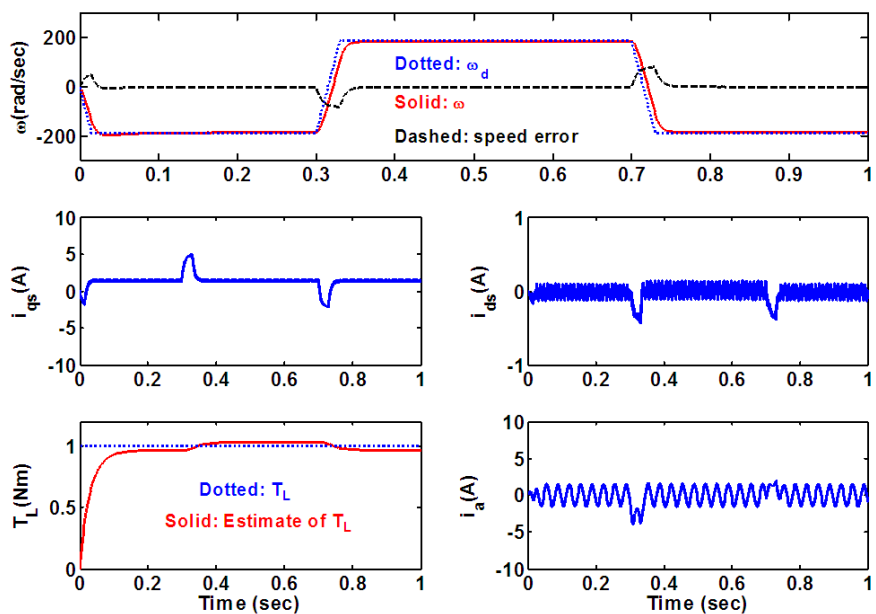

Fig.7. Simulation results of the proposed control method $\left(N_{\mathrm{o}}=0\right.$ and $\left.N=0\right)$ under Case 1.
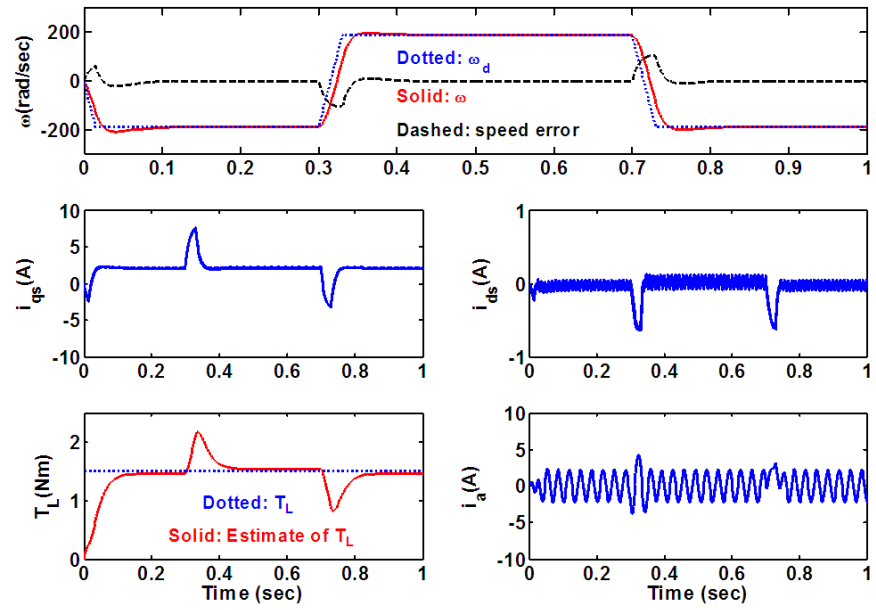

Fig. 8. Simulation results of the proposed control method $\left(N_{\mathrm{o}}=0\right.$ and $\left.N=0\right)$ under Case 2. 

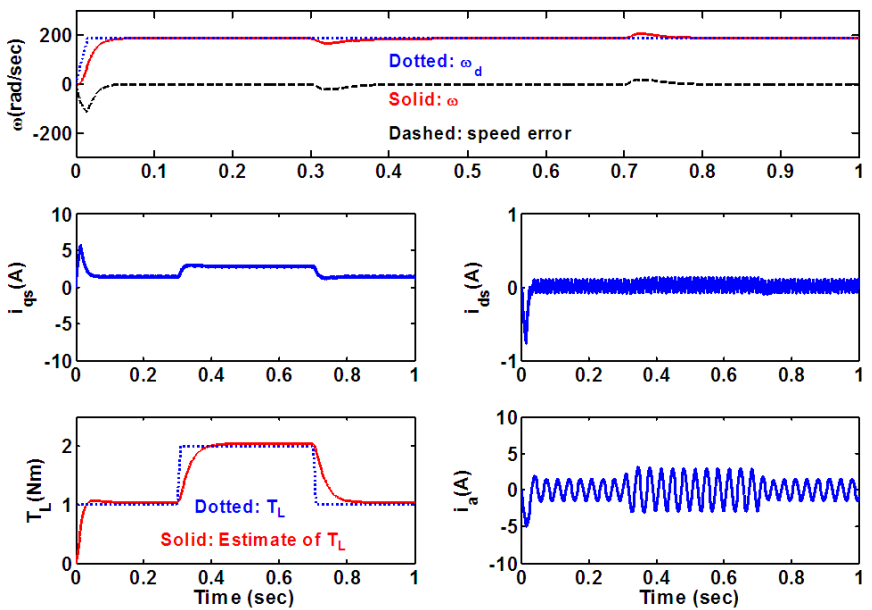

Fig. 9. Simulation results of the proposed control method $\left(N_{\mathrm{o}}=0\right.$ and $\left.N=0\right)$ under Case 3.
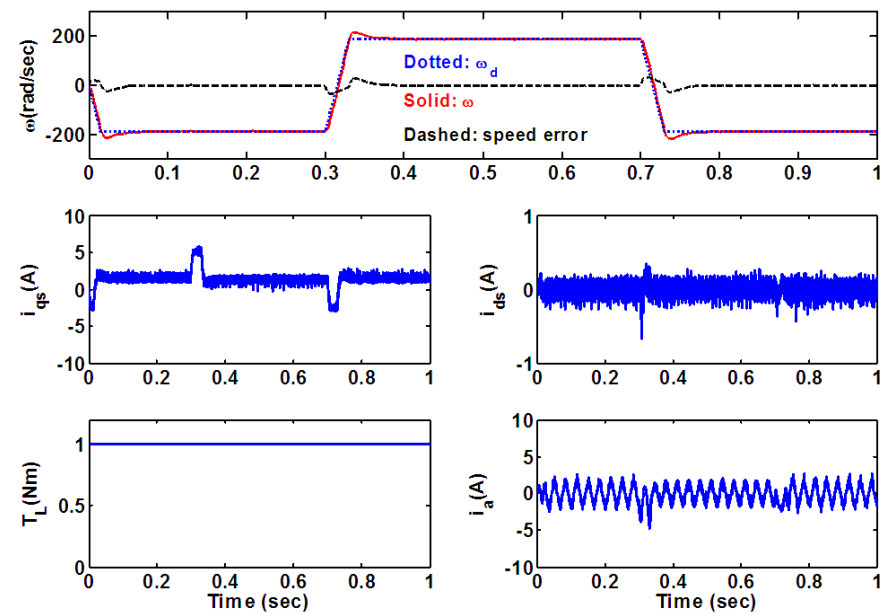

Fig. 10. Simulation results of the conventional PI-PI control method under Case 1.
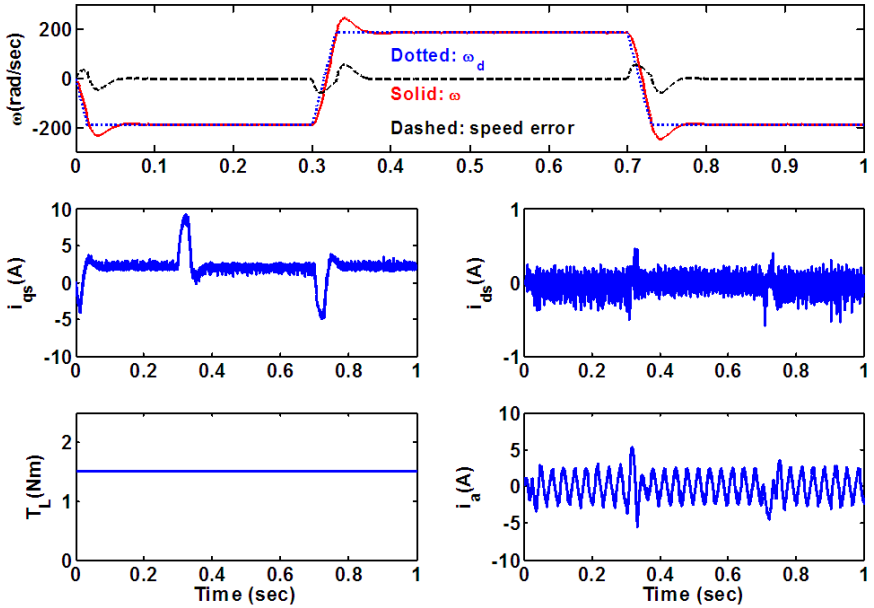

Fig. 11. Simulation results of the conventional PI-PI control method under Case 2 .
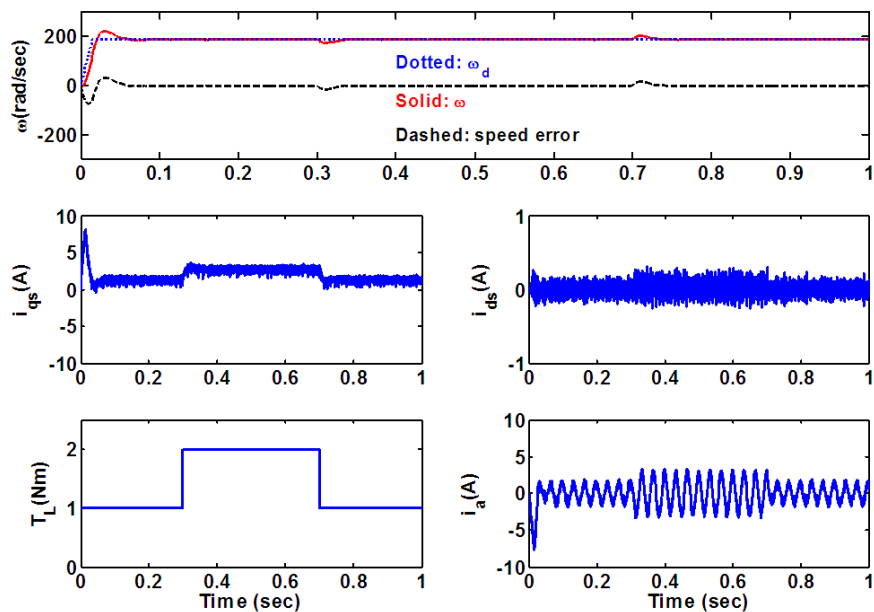

Fig. 12. Simulation results of the conventional PI-PI control method under Case 3.
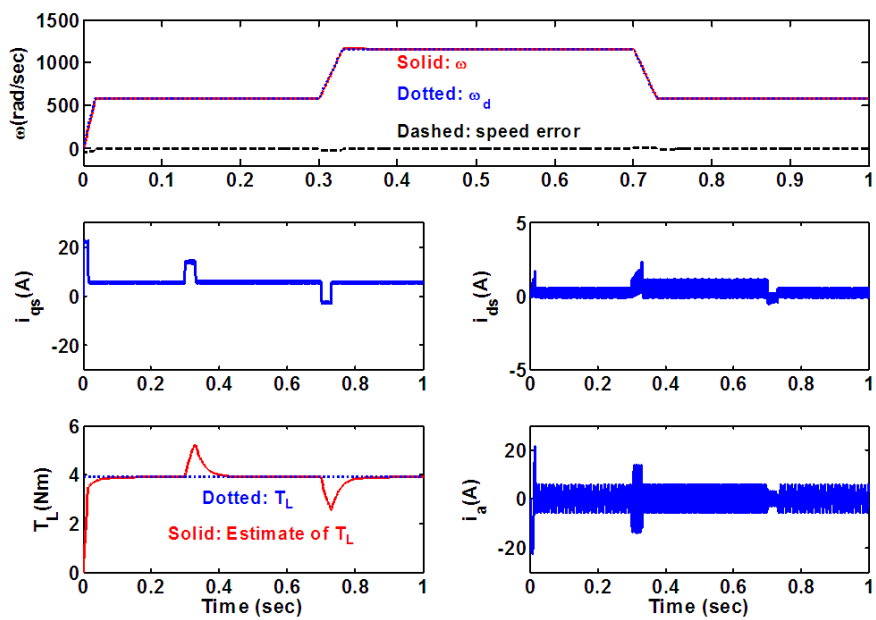

Fig. 13. Simulation results of the proposed control method $\left(N_{\mathrm{o}}=1\right.$ and $\left.N=1\right)$ under $150 \%$ variations of some motor parameters $\left(R_{S}, L_{S}, J\right)$ when the reference speed increases up to the rated value (1850 RPM).

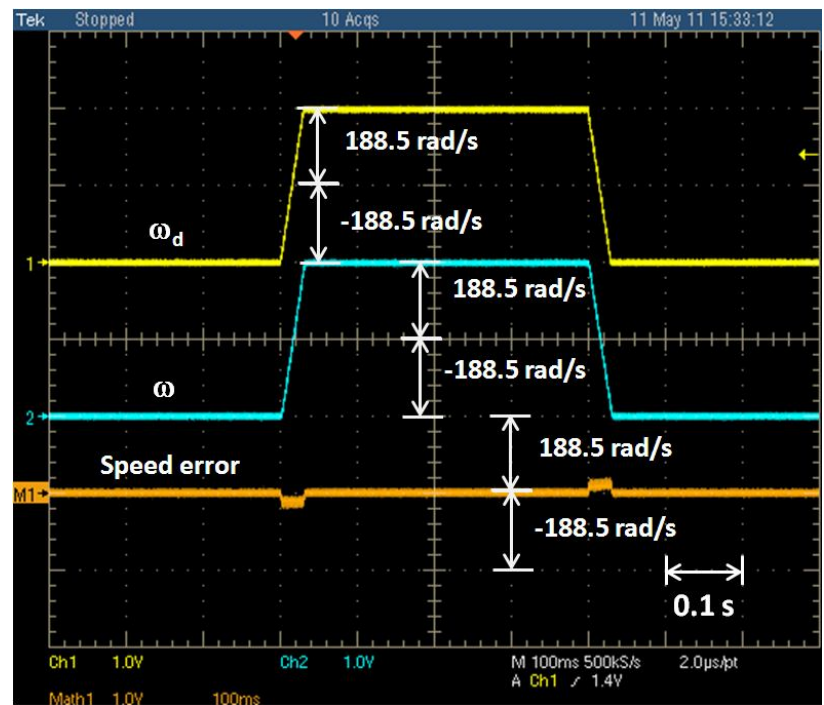

(a) Desired speed $\left(\omega_{d}\right)$, measured speed $(\omega)$, and speed error $(\tilde{\omega})$ 


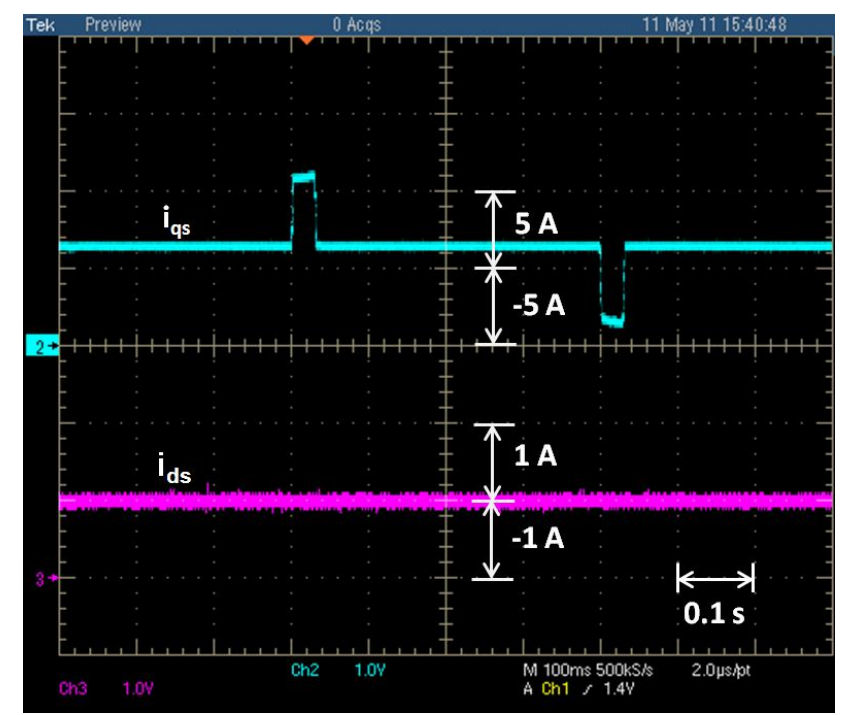

(b) $q$-axis current $\left(i_{q s}\right)$ and $d$-axis current $\left(i_{d s}\right)$

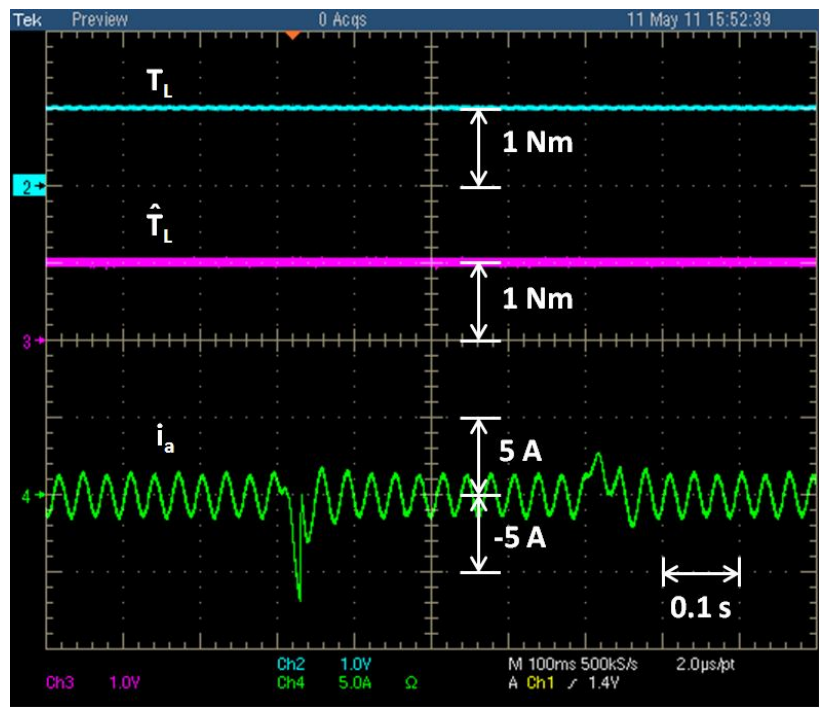

(c) Load torque $\left(T_{L}\right)$, estimated load torque $\left(\hat{T}_{L}\right)$ and phase $a$ current $\left(i_{a}\right)$

Fig. 14. Experimental results of the proposed control method $\left(N_{\mathrm{o}}=1, N=1\right)$

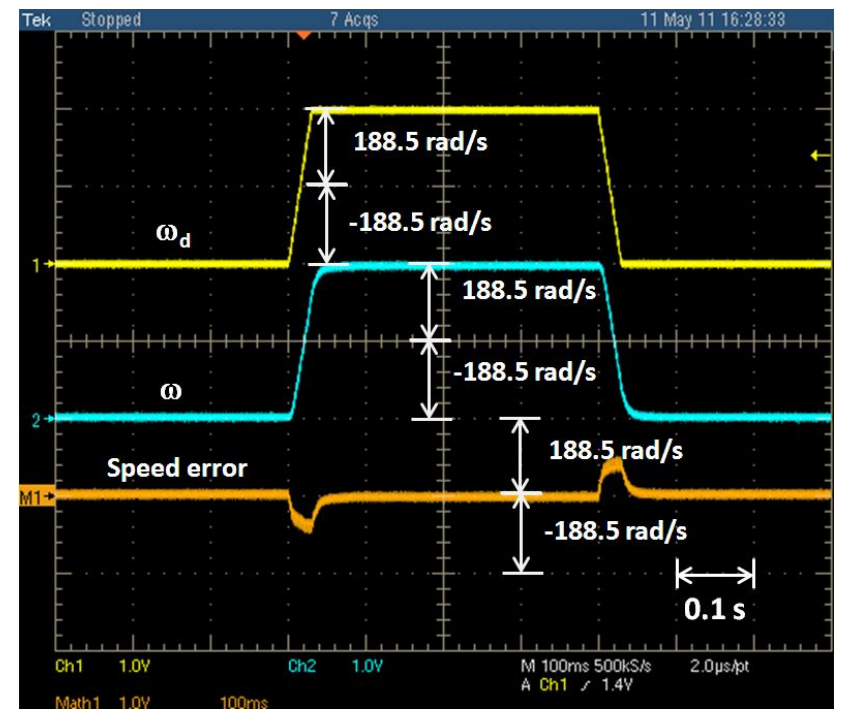

(a) Desired speed $\left(\omega_{d}\right)$, measured speed $(\omega)$, and speed error $(\tilde{\omega})$

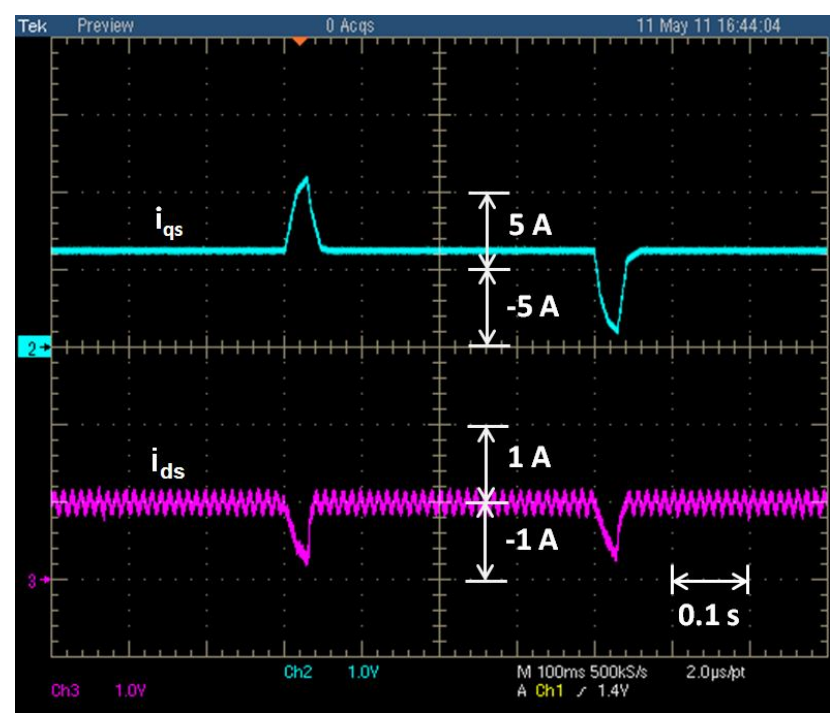

(b) $q$-axis current $\left(i_{q s}\right)$ and $d$-axis current $\left(i_{d s}\right)$

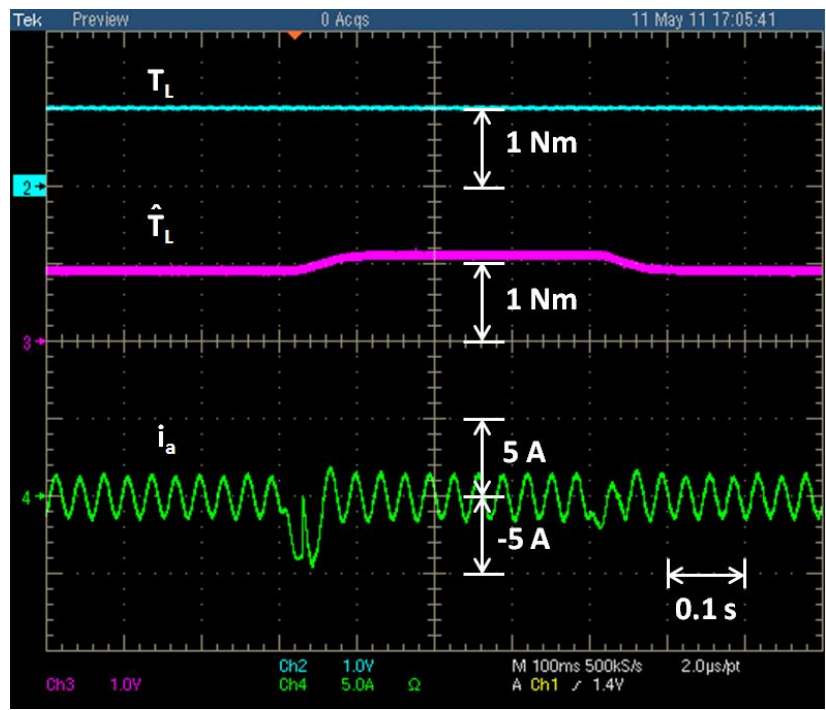

(c) Load torque $\left(T_{L}\right)$, estimated load torque $\left(\hat{T}_{L}\right)$ and phase $a$ current $\left(i_{a}\right)$

Fig. 15. Experimental results of the proposed control method $\left(N_{\mathrm{o}}=0, N=0\right)$.

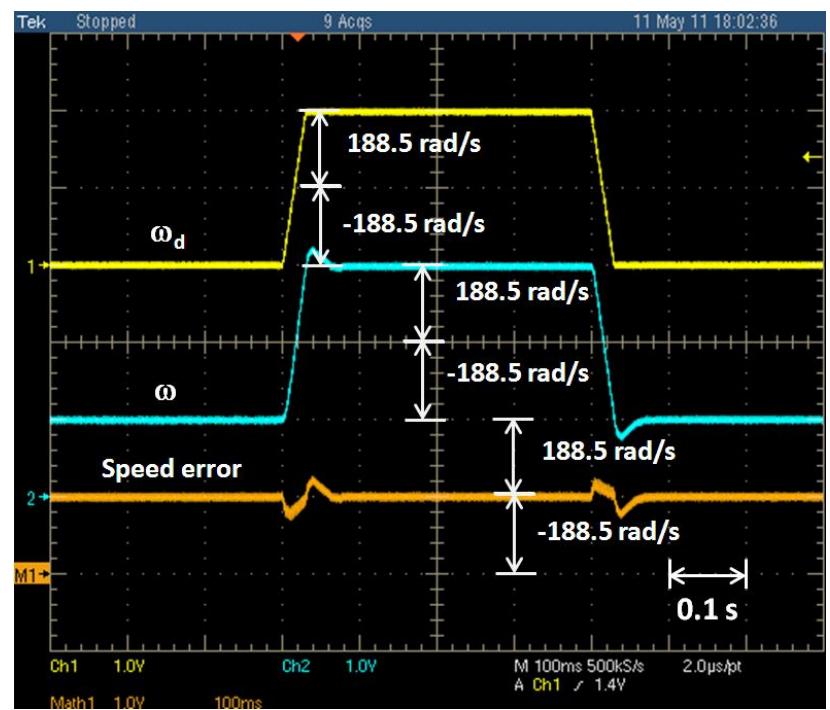

(a) Desired speed $\left(\omega_{d}\right)$, measured speed $(\omega)$, and speed error $(\tilde{\omega})$ 


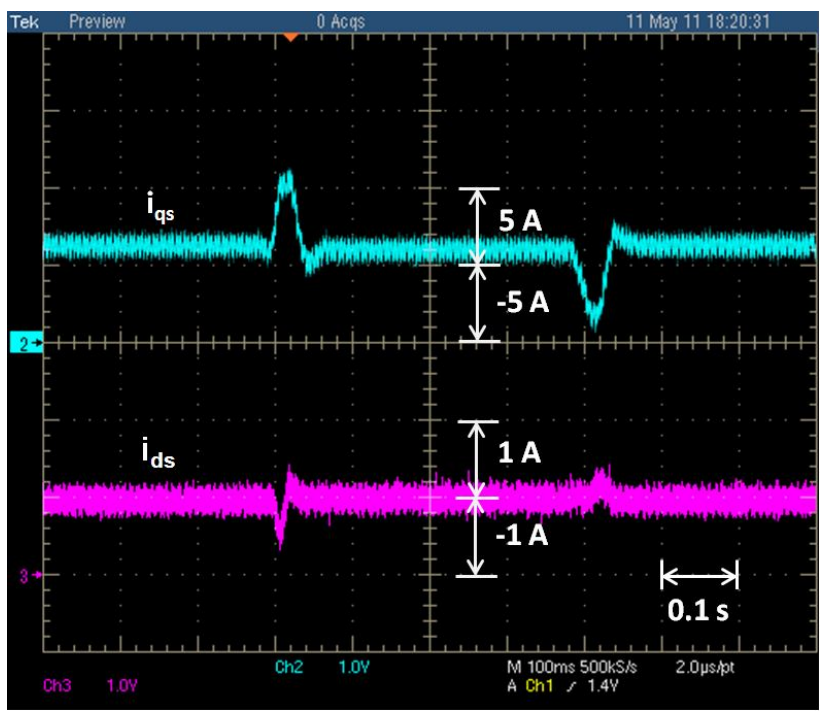

(b) $q$-axis current $\left(i_{q s}\right)$ and $d$-axis current $\left(i_{d s}\right)$

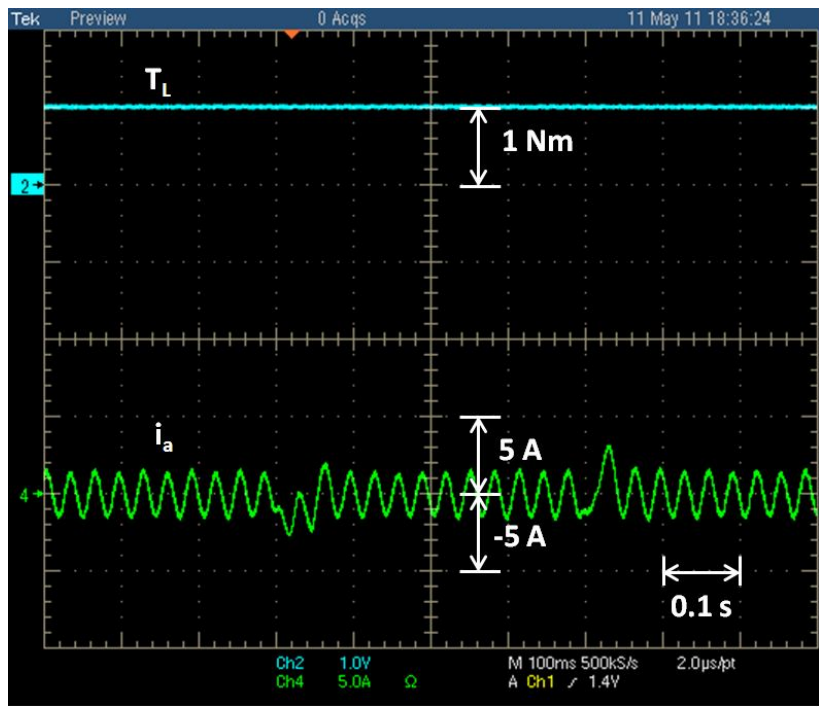

(c) Load torque $\left(T_{L}\right)$ and phase $a$ current $\left(i_{a}\right)$

Fig. 16. Experimental results of the conventional PI-PI control method.

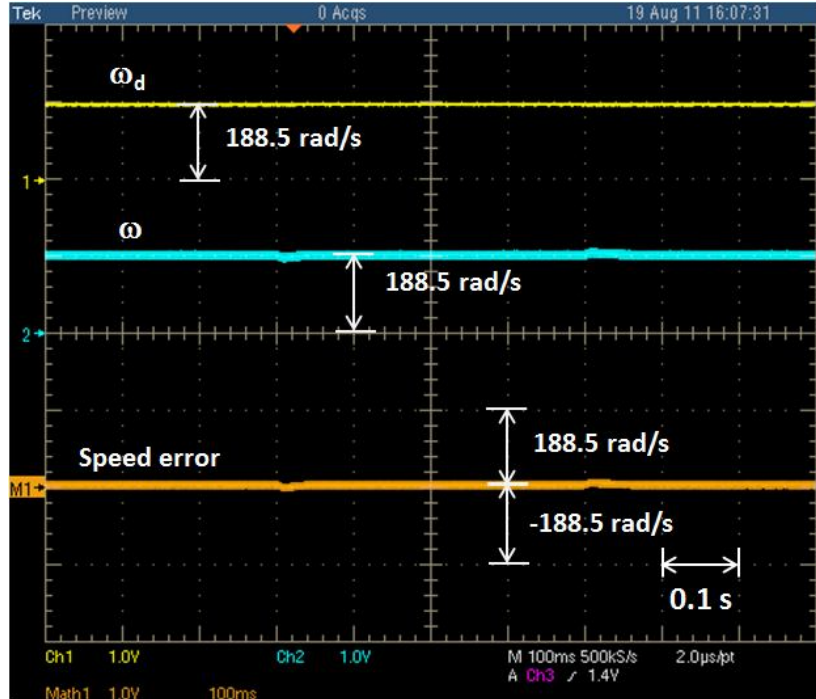

(a) Desired speed $\left(\omega_{d}\right)$, measured speed $(\omega)$, and speed error $(\tilde{\omega})$

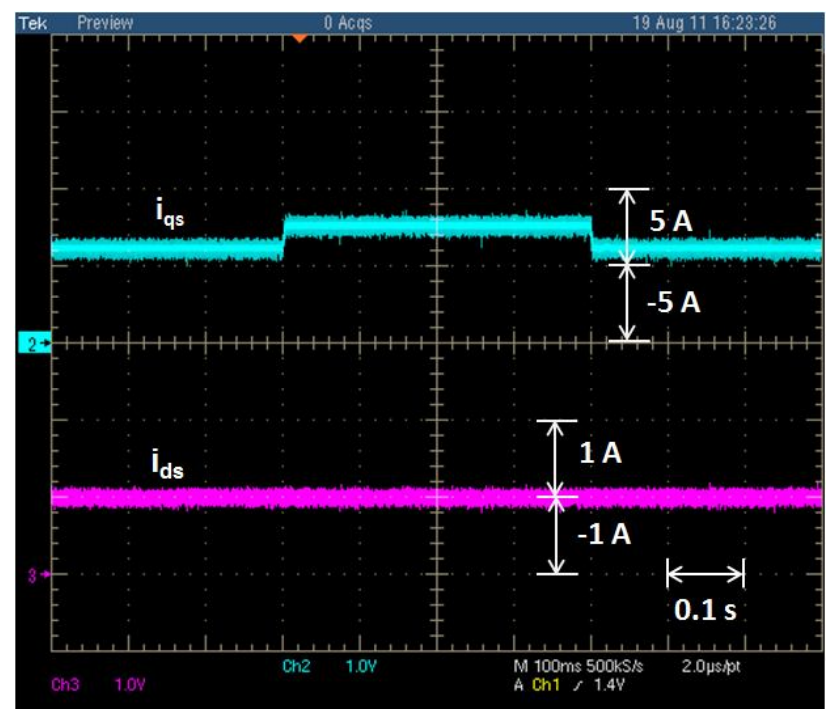

(b) $q$-axis current $\left(i_{q s}\right)$ and $d$-axis current $\left(i_{d s}\right)$

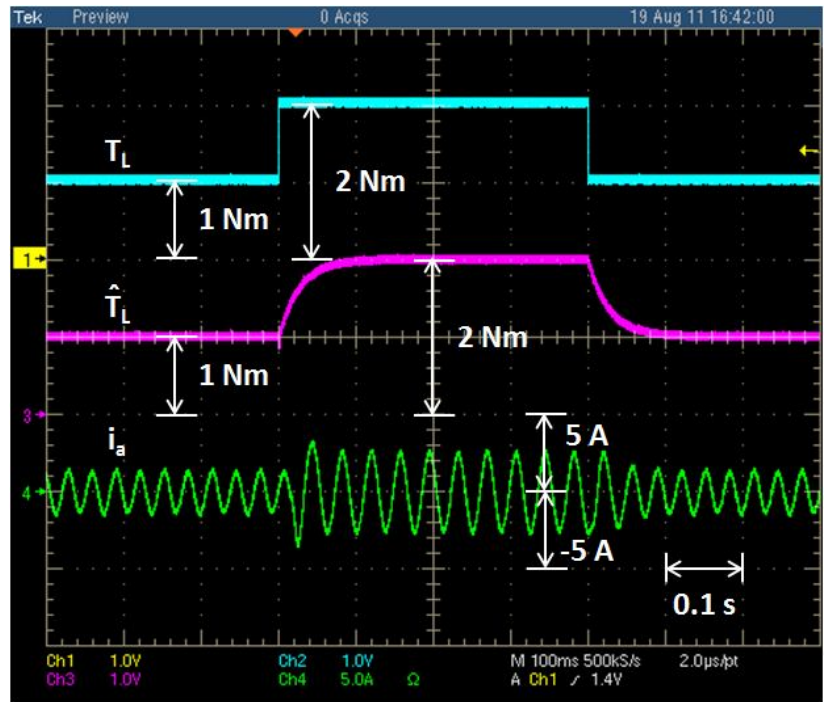

(c) Load torque $\left(T_{L}\right)$, estimated load torque $\left(\hat{T}_{L}\right)$ and phase $a$ current $\left(i_{a}\right)$

Fig. 17. Experimental results of the proposed control method $\left(N_{\mathrm{o}}=1\right.$ and $N=1)$ under $150 \%$ variations of some motor parameters $\left(R_{s}, L_{\S}, J\right)$ when the load torque changes with a step.

From the simulation and experimental results, it is definitely proven that the proposed SDRE-based near optimal control scheme can achieve better control performance such as no overshoot, zero steady-state error, and fast transient response in speed tracking than the linear conventional control methods such as LQ regulator and PI controller in the presence of the motor parameter and load torque variations.

\section{CONCLUSION}

An SDRE-based near optimal controller and observer are proposed to exactly track a reference trajectory of a PMSM. In both designs, the stability is analytically proven and Taylor series numerical method approximates the solution of each SDRE which cannot be solved directly. To verify the effectiveness of the proposed control strategy, simulations have been performed with Matlab/Simulink program and 
experiments have been implemented with a PMSM drive using a TMS320F28335 DSP. It has been shown that the proposed SDRE-based near optimal control algorithm can guarantee better control performance (e.g., no overshoot, zero steady-state error, and fast transient response) in speed tracking capability than the linear conventional control methods (e.g., LQ regulator and PI controller) even under the variations of the motor parameters and load torque.

\section{REFERENCES}

[1] J. Lee, J. Hong, K. Nam, R. Ortega, L. Praly, and A. Astolfi, "Sensorless control of surface-mount permanent-magnet synchronous motors based on a nonlinear observer," IEEE Trans. Power Electron., vol. 25, no. 2, pp. 290-297, Feb. 2010

[2] H. S. Kang, C. K. Kim, and Y. S. Kim, "Position control for interior permanent magnet synchronous motors using an adaptive integral binary observer," Journal of Electrical Engineering \& Technology, vol. 4, no. 2, pp. 240-248, Jun. 2009

[3] V. M. Hernandez-Guzman and R. Silva-Ortigoza, "PI control plus electric current loops for PM synchronous motors," IEEE Trans. Contr. Syst. Tech., vol. 19, no. 4, pp. 868-873, Jul. 2011.

[4] S. J. Underwood and I. Husain, "Online parameter estimation and adaptive control of permanent-magnet synchronous machines," IEEE Trans. Ind. Electron., vol. 57, no. 7, pp. 2435-2443, Jul. 2010.

[5] H. H. Choi, N. T. T. Vu, and J. W. Jung, "Digital implementation of an adaptive speed regulator for a PMSM," IEEE Trans. Power Electron., vol. 26, no. 1, pp. 3-8, Jan. 2011.

[6] A. Akrad, M. Hilairet, and D. Diallo, "Design of a fault-tolerant controller based on observers for a PMSM drive," IEEE Trans. Ind. Electron., vol. 58, no. 4, pp. 1416-1427, Apr. 2011.

[7] K. Raggl, B. Warberger, T. Nussbaumer, S. Burger, and J. W. Kolar, "Robust angle-sensorless control of a PMSM bearing Pump," IEEE Trans. Ind. Electron., vol. 56, no. 6, pp. 2076-2085, Jun. 2009.

[8] F. F. M. El-Sousy, "Hybrid $H_{\infty}$-based wavelet-neural network tracking control for permanent-magnet synchronous motor servo drive," IEEE Trans. Ind. Electron., vol. 57, no. 9, pp. 3157-3166, Sep. 2010.

[9] H. Kim, J. Son, and J. Lee, "A high-speed sliding-mode observer for sensorless speed control of a PMSM," IEEE Trans. Ind. Electron., vol. 58, no. 9, pp. 4069-4077, Sep. 2011

[10] C. Orgega, A. Arias, C. Caruana, J. Balcells, and G. M. Asher, "Improved waveform quality in the direct torque control of matrixconverter-fed PMSM drives," IEEE Trans. Ind. Electron., vol. 57, no. 6, pp. 2101-2110, Jun. 2010.

[11] K. Hartani, Y. Miloud, and A. Miloudi, "Improved direct torque control of permanent magnet synchronous electrical vehicle motor with proportional-integral resistance estimator," Journal of Electrical Engineering \& Technology, vol. 5, no. 3, pp. 451-461, Sep. 2010

[12] M. Preindl and E. Schaltz, "Sensorless model predictive direct current control using novel second-order PLL observer for PMSM drive systems," IEEE Trans. Ind. Electron., vol. 58, no. 9, pp. 4087-4095, Sep. 2011.

[13] Y. S. Kung, C. C. Huang, and M. H. Tsai, "FPGA realization of an adaptive fuzzy controller for PMLSM drive," IEEE Trans. Ind. Electron., vol. 56, no. 8, pp. 2923-2932, Aug. 2009.

[14] D. K. Parrish and D. B. Ridgely, "Control of an artificial human pancreas using the SDRE method," in Proc. ACC, New Mexico, USA, Jun. 1997, pp. 1059-1060.

[15] A. Theodoropoulou, R. A. Adomaitis, and E. Zafifiou, "Model reduction for optimization of rapid thermal chemical vapor deposition systems," IEEE Trans. Semicond. Manuf., vol. 11, no. 1, pp. 85-98, Feb. 1998.

[16] D. T. Stansbery and J. R. Cloutier, "Position and attitude control of a spacecraft using the state-dependent Riccati equation technique," in Proc. ACC, Illinois, USA, Jun. 2000, pp. 1867-1871.

[17] E. B. Erdem and A. G. Alleyne, "Experimental real-time SDRE control of an underactuated robot," in Proc. IEEE ACC, Florida, USA, 2001, pp. 2986-2991.

[18] M. Sznaier, J. Cloutier, R. Hull, D. Jacques, and C. Mracek, "A receding horizon state dependent Riccati equation approach to suboptimal regulation of nonlinear systems," in Proc. $37^{\text {th }}$ IEEE CDC Dec. 16-18, 1998, vol. 2, pp. 1792-1797.

[19] E. B. Erdem and A. G. Alleyne, "Globally stabilizing second-order nonlinear systems by SDRE control," in Proc. IEEE ACC, California, USA, 1999, pp. 2501-2505.

[20] J. Pittner and M. A. Simaan, "A useful control model for tandem hot metal strip rolling," IEEE Trans. Ind. Appl., vol. 46, no. 6, pp. 22512258, Nov./Dec. 2010.

[21] I. Chang, S. Y. Park, and K. H. Choi, "Nonlinear attitude control of a tether-connected multi-satellite in three-dimensional space," IEEE Trans. Aeros. Electron., vol. 46, no. 4, pp. 1950-1968, Oct. 2010.

[22] P. V. Medagam, T. Yucelen, and F. Pourboghrat, "Adaptive SDREbased nonlinear sensorless speed control for PMSM drives," in $37^{\text {th }}$ IEEE NAPS, Illinois, USA, Sept. 30-Oct. 2, 2007, pp. 518-522.

[23] H. Beikzadeh and H. D. Taghirad, "Nonlinear sensorless speed control of PM synchronous motor via an SDRE observer-controller combination," in $4^{\text {th }}$ IEEE ICIEA, Xi'an, China, May 25-27, 2009, pp. 3570-3575.

[24] H. T. Bank, B. M. Lewis, and H. T. Tran, "Nonlinear feedback controllers and compensators: a state-dependent Riccati equation approach," J. Comput. Optim. Appl., vol. 37, no. 2, pp. 177-218, Mar. 2007

[25] A. Wernli and G. Cook, "Suboptimal control for the nonlinear quadratic regulator problem," Automatica, vol.11, no. 1, pp. 75-84, Jan. 1975.

[26] P. Kshirsagar, R. P. Burgos, A. Lidozzi, J. Jang, F. Wang, D. Boroyevich, and S.-K. Sul, "Implementation and sensorless vectorcontrol design and tuning strategy for SMPM machines in fan-type applications," IEEE Ind. Applicat. Conf. IAS Annu. Meeting, 2006, vol. 4, pp. 2062-2069.

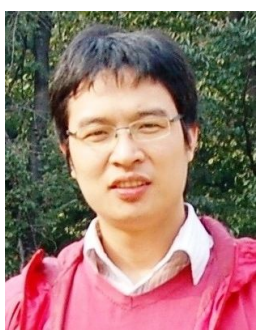

Ton Duc Do received the B.S. and M.S. degrees in electrical engineering from Hanoi University of Technology, Hanoi, Vietnam in 2007 and 2009, respectively. $\mathrm{He}$ is currently pursuing the Ph.D. degree in the Division of Electronics and Electrical Engineering, Dongguk University, Seoul, Korea. His research interests are in the field of electric machine drives and control of distributed generation systems using renewable energy sources.

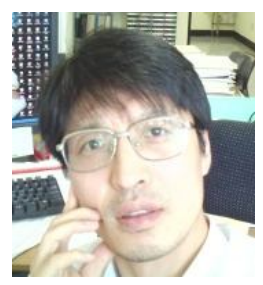

Han Ho Choi (M'03) received the B.S. degree in control and instrumentation engineering from SNU, Seoul, Korea, in 1988, and the M.S. and Ph.D. degrees in electrical engineering from KAIST, Daejeon, Korea, in 1990 and 1994, respectively. He is currently with the Division of Electronics and Electrical Engineering, Dongguk University, Seoul, Korea. His research interests include control theory and its application to real world problems.

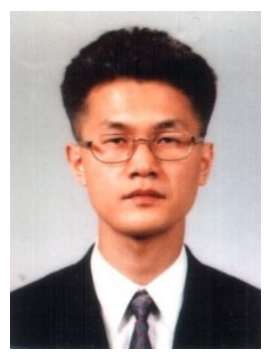

Jin-Woo Jung (S'97-M'06) received the B.S. and M.S. degrees in electrical engineering from Hanyang University, Seoul, Korea in 1991 and 1997, respectively, and the Ph.D. degree in Electrical and Computer Engineering from The Ohio State University, Columbus, Ohio, USA, in 2005. From 1997 to 2000, he was with the Digital Appliance Research Laboratory, LG Electronics Co., Ltd., Seoul, Korea. From 2005 to 2008, he worked at the R\&D Center and PDP Development Team, Samsung SDI Co., Ltd., Korea, as a senior engineer. Since 2008, he has been an Assistant Professor with the Division of Electronics and Electrical Engineering, Dongguk University, Seoul, Korea. His current research interests are in the area of electric machine drives, control of 
distributed generation systems using renewable energy sources (wind turbines/fuel cells, solar cells), design and control of power converters, and driving circuits and driving methods of ac plasma display panels (PDP). 